\title{
Evidencia empírica micro-regional del impacto de la política económica en el sub-sector de granos básicos*
}

$\mathrm{E}$ 1 presente artículo, el primero de una serie de dos, tiene como objetivo hacer una evaluación, partiendo de la evidencia empírica microregional $^{1}$, del impacto de las políticas del gobiemo en el comportamiento económico de los pequeños productores agropecuarios. En el segundo artículo se plantearán las recomendaciones que desde la perspectiva micro-regional, se pueden hacer al subsector de granos básicos del país; además, se agrega un anexo que presenta una mayor evidencia sobre lo que se ha llamado el efecto subsistencia-producto en la producción de granos básicos ${ }^{2}$ y su importancia para la política económica.

Para alcanzar lo que se persigue con este primer artículo, se hará uso de los datos recogidos en las encuestas cursadas en dos municipios: San Juan Opico, departamento de la Libertad, y Tecoluca, departamento de San Vicente. Considerando la objeción innegable que puede hacerse a la extrapolación de resultados encontrados a nivel de las micro-regiones al comportamiento global de los pequeños productores agropecuarios, especialmente de granos básicos, hemos tenido que recurrir en todo momento a los resultados que se obtuvieron de la investigación sobre el impacto de la política económica del gobierno en el subsector de granos básicos de todo El Salvador, investigación realizada en el contexto del Proyecto de Análisis ${ }^{3}$ de la Política Agropecuaria, con el fin expreso de que sirviera de marco de referencia a la evaluación que con respecto del impacto de la política económica en las micro-regiones se obtuviera. La conclusión a la que se llega derivada de este proceso de comparación es que, en

* El presente artículo es un producto derivado del Proyecto Análisis de la Política Agraria, financiado por la Fundación FORD en 1995. 
general, los efectos de la política económica que se constataron a nivel global del subsector de granos básicos, también se muestran en los dos municipios estudiados; de manera que, aparte de las magnitudes las cuales como es obvio son diferentes, el análisis que se hace para la micro-región tienen representatividad para abordar el caso de la situación de todos los pequeños productores agropecuarios, en especial de granos básicos, del país.

Es difícil poder determinar el impacto de las políticas económicas del gobierno, sólo partiendo de los resultados recabados en encuestas; principalmente cuando éstas son de carácter estático, es decir, sin incluir series de tiempo en los datos, y cuando se hallan referidas, por las mismas características de los encuestados, a un determinado sub-sector de la economía; la primera limitación vuelve imposible poder determinar comportamientos en períodos largos, aunque posiblemente no excluya un análisis de corte transversal y/o de corto plazo; mientras que la segunda limitación se traduce en la escasez de datos y estudios pormenorizados y sistemáticos, tanto a nivel regional como nacional, que ayuden a sustentar las posibles tendencias que se pudiesen detectar a través de los resultados de la encuesta.

Haciendo frente a esas dificultades, y utilizando la poca información que se tiene de la situación del sub-sector de granos básicos a nivel de todo el país, se ha podido elaborar este artículo que hemos dividido en dos apartados muy relacionados con lo que fue posible evidenciar a través del estudio de campo; un primer apartado, se refiere al efecto de las políticas económicas en la situación de los ingresos y gastos de los productores de los dos municipios, para lo cual se vuelve fundamental no sólo retomar las pruebas empíricas que se han podido recoger en el campo, sino también los comportamientos observados a nivel nacional. El segundo apartado, intentar presentar evidencias que señalen las vinculaciones que se hallan entre la situación socio-económica de los productores y el problema ecológico y de la economía familiar, acerca de esto no se tiene información abundante, por lo que este apartado debe tomarse más con carácter intuitivo que definitivo. Demos paso, entonces, al primer apartado.

\section{A. El efecto en la situación de los ingresos y gastos}

Presentar las condiciones socio-económicas de los pequeños productores agropecuarios de las micro-regiones, utilizando variables como los gastos, los rendimientos, los precios y los ingresos, no los transforma por sí mismos en pruebas del impacto que la política económica ha tenido en ellos; para poder determinar esto último se vuelve necesario que, a falta de una comparación temporal entre los datos nacionales del sub-sector y los micro-regionales, se haga una comparación estática haciendo uso de determinados criterios y supuestos realistas que nos permitan deducir cómo las políticas han afectado la activi- 
dad y las condiciones socio-económicas de los productores; sin embargo, no descartamos que, de poseer información, podamos hacer algunos análisis dinámicos, acerca de determinadas variables claves.

Antes de establecer cuáles han sido los principales impactos de las políticas económicas del gobierno en el sub-sector, es importante tratar de conocer el marco conceptual que anima las políticas y el sistema de éstas que se levanta sobre dicho marco, así como los fines que se persiguen con las mismas. De este modo, cuando se muestran los resultados, se hace más fácil determinar cómo se explican.

\section{A.1. El marco conceptual de la política económica del gobierno.}

Hasta ahora se conoce que el gobiemo, tanto el anterior como el actual, se han declarado partidarios de la corriente neoliberal; en los programas se han definido los principios fundamentales de este enfoque que, al momento de compararlos con el credo neoliberal de W. Eucken, fundador hace más de 50 años en Alemania de esta corriente, se observa que se encuentran inspirados al pie de la letra en las líneas señaladas por Eucken; no obstante, hasta teniendo esa información e incluso la relacionada a la manera en que se implementaron y funcionaron las medidas de política económica en Alemania, cuna del neoliberalismo, se vuelve difícil, si no imposible, tratar de determinar cuáles son las características específicas conceptuales del neoliberalismo salvadoreño; este vacío crea la impresión de inseguridad y falta de claridez por parte del gobierno, en el sentido de que mientras no se establezcan reglas claras, sencillamente las puede estar cambiando de forma errática sin incurrir severamente en el desprestigio público del gobierno, aunque el efecto sí perjudique a amplios sectores sociales en su actividad y sobrevivencia económica.

Pero los asesores del gobierno, considerando que técnicamente toda política económica debe tener una clara definición, principalmente cuando se ha publicitado tanto; han tratado de diseñar lo que podría llamarse las líneas teóricas generales de la política económica neoliberal salvadoreña. De este modo, en el Informe de Coyuntura de octubre de 1994, editado por la UAP/MAG, se presenta un extracto de un trabajo más amplio de Hugo Ramos y Comelius Hugo, consultores del gobierno, titulado "Estado y mercado: un enfoque de política económica", en este artículo se exponen de forma breve en qué consiste el modelo que es la fuente teórica del diseño de políticas económicas del gobierno.

De acuerdo con estos autores, los enfoques de política económica se pueden dividir en tres: el modelo de Estado intervencionista, el modelo liberal y el modelo pragmático. Luego, plantean que aunque los supersimplificados supuestos de los primeros dos enfoques son acertados, olvidan la importancia de factores institucionales que sí se incluyen en el tercero. 
Así, la hipótesis de partida del enfoque intervencionista y el liberal se puede escribir como sigue: "Los precios, se supone acertadamente, son los elementos que condicionan el nivel de ingreso de los agentes económicos hogares, en forma más general. A su vez, es el factor crítico y fundamental del bienestar de los hogares, sjendo su deficiencia la razón esencial de la pobreza".

En el primer enfoque, el Estado, que es considerado sin mayores miramientos por estos autores como una institución de naturaleza "neutral", se propone alcanzar el bienestar de los hogares y para ello, dado el carácter estratégico que tienen los precios en la cadena del esquema elemental que se ha establecido (ver figura 1), decide intervenir el sistema de precios; el resultado, en opinión de ellos, "...es un sector plagado de distorsiones, carentes de estímulos para la inversión pero abundantes en oportunidades para obtención de rentas. La incertidumbre y la desconfianza son factores persistentes en las actividades económicas y, especialmente, en las de mercadeo. Si a estas características se añaden el incremento en el gastos fiscal (déficit) y la creciente presión inflacionaria que genera, es fácil concluir que el sector ofrece un clima desfavorable para la inversión".

FIGURA 1. POLITICA ECONOMICA INTERVENCIONISTA

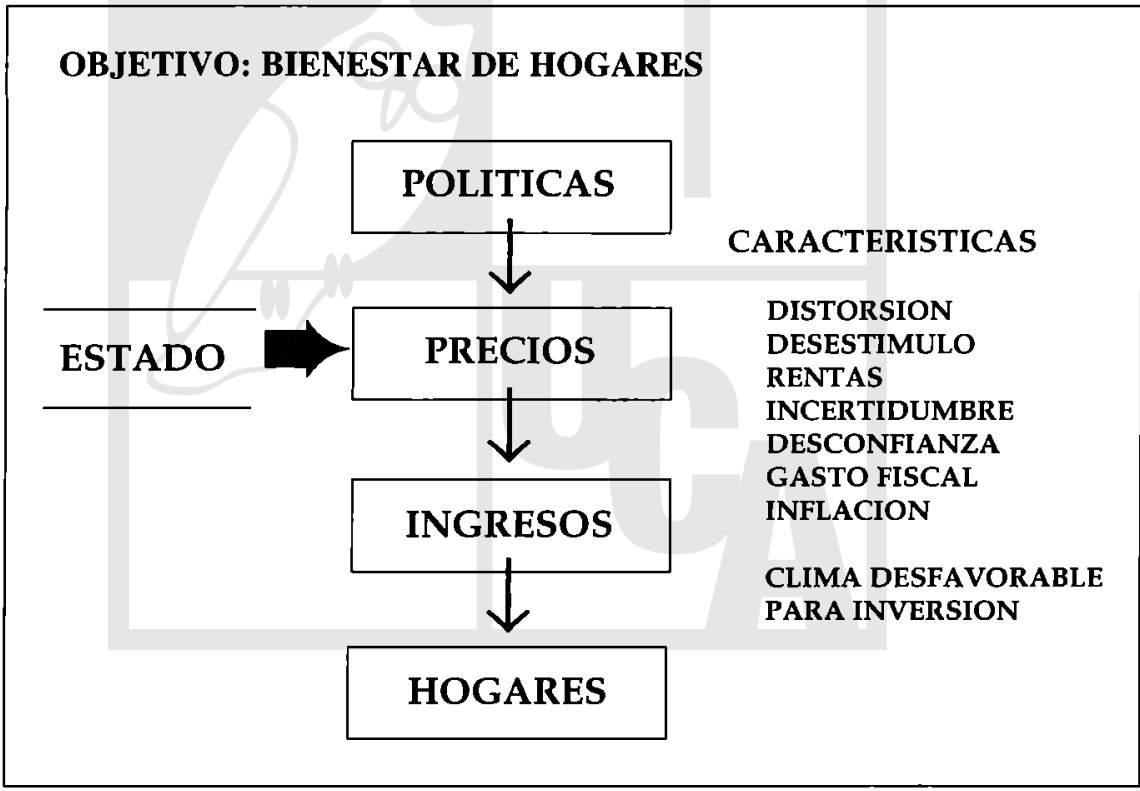

Fuente: UAP, MAG. Informe de coyuntura, octubre, 1994. 
En el modelo liberal, el estado se halla totalmente marginado y no tiene ninguna intervención, el mercado es el que regula el sistema de precios (figura 2). "Los llamados programas de estabilización y de ajuste estructural han buscado precisamente reducir el papel del Estado en la economía y propugnar el rol de ejecutor de la economía al sector privado". Aunque los autores enfatizan que la eficiencia económica se mejora ineludiblemente con este modelo, “... quedan algunas preguntas sin respuestas claras respecto a la bondad del modelo en términos de equidad económica y de integración al mercado de grupos poblacionales menos favorecidos". Por lo visto se acepta un carácter inherentemente marginante de este modelo, a lo cual no da solución alguna, empero, aun tomando en cuenta este defecto, que no puede ser considerado de poca monta, los autores en cuestión enfatizan en lo que ellos consideran la virtud principal de este modelo: "Se espera que el mercado competitivo, con un mercado reforzado por un comercio externo más libre, al mismo tiempo que promueve la eficiencia, propulse también una distribución más equitativa. El crecimiento, la estabilidad y la confianza son características adicionales que crean un clima favorable para la inversión en el sector".

FIGURA 2. POLITICA ECONOMICA: LIBRE MERCADO

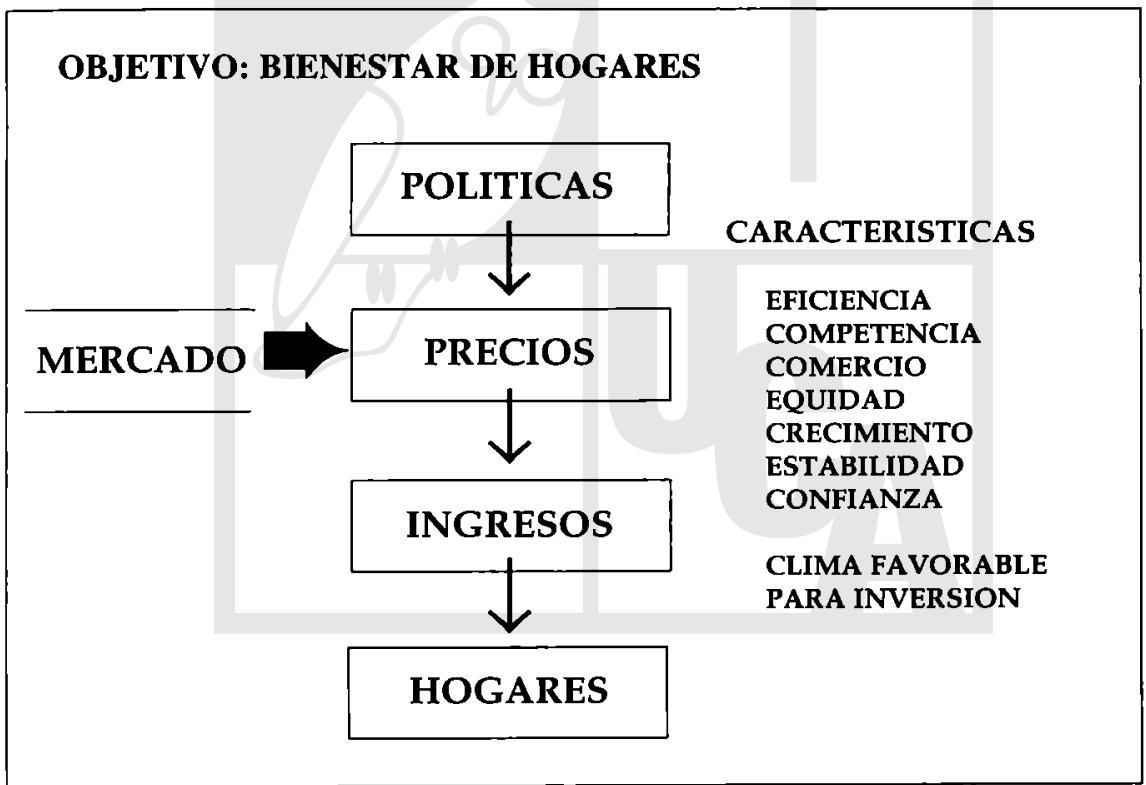

Fuente: Ibid. 
Todo el énfasis, en las "ventajas" del segundo modelo, se explica cuando los autores plantean su enfoque "pragmático", que no es otra cosa que la modernización del planteamiento de Smith sobre la mano invisible y las obligaciones del Estado, con los refinamientos relativos a los efectos negativos de los monopolios y/o los oligopolios y la necesidad de que el Estado se limite a un papel normativo y subsidiario de manera que, en palabras de Smith, "... únicamente tiene tres deberes que cumplir, los tres muy importantes, claros e ininteligibles al intelecto humano: el primero, defender a la sociedad contra la violencia e invasión de otras sociedades independientes; el segundo, proteger en lo posible a cada uno de los miembros de la sociedad de la violencia y de la opresión de que pudiera ser víctima por parte de otros individuos de esa misma sociedad, estableciendo una recta administración de justicia; y el tercero, la de erigir y mantener ciertas obras y establecimientos públicos cuya erección y sostenimiento no pueden interesar a un individuo o a un pequeño número de ellos, porque las utilidades no compensan los gastos que pudiera haber hecho una persona o un grupo de éstas, aun cuando sean frecuentemente muy remuneradoras para el gran cuerpo social" (Adam Smith, Riqueza de las naciones, capítulo IX).

Dado que el "enfoque pragmático" no solamente considera que los precios influyen en los ingresos, sino también lo que llaman "costos de transacción" que son aquellos que dependen de las reglas y normas de la sociedad, y que aumentan cuando estas no son claras, se encuentran mal diseñadas o son desconocidas por los interesados; las políticas económicas deben ser preparadas comprendiendo que la conexión de éstas "... con los precios no es directa sino que ocurre a través de los mercados y las instituciones", lo cual debe generar costos de transacción que deben ser minimizados por las políticas institucionales. La primera de las variables, los precios, se vincula con el mercado y debe ser regida por ésta, la segunda tiene que ver con las instituciones las cuales deben ser normadas por el Estado; el efecto combinado de los costos de transacción y los precios determinan los ingresos y el bienestar de los hogares (ver figura 3 en página siguiente).

Por cuanto las estructuras de mercado se desenvuelven en un marco institucional y pueden ser de diversos tipos, algunas de las cuales - como las estructuras monopólicas u oligopólicas - resultan en situaciones de "ineficiencia, desigualdad, oportunismo, desempleo y pobreza", las políticas institucionales deben establecer acciones firmes y efectivas "para promover la competencia, para ampliar la propiedad del capital, para permitir la integración a los mercados de grupos segregados de la economía".

El "modelo pragmático" se reduce, pues, a que el papel normativo y subsidiario del Estado, que posee un carácter neutral, asegure un entorno institucional que permita el perfecto funcionamiento de "la mano invisible", esto es, de un mercado competitivo el cual determina un precio correcto. "El comportamiento 
de los agentes en este tipo de mercado es competitivo. El desempeño en este mercado resulta en eficiencia, equidad, mayor empleo, mejores salarios, menos pobreza, mayor bienestar social".

FIGURA 3. POLITICA ECONOMICA PRAGMATICA.

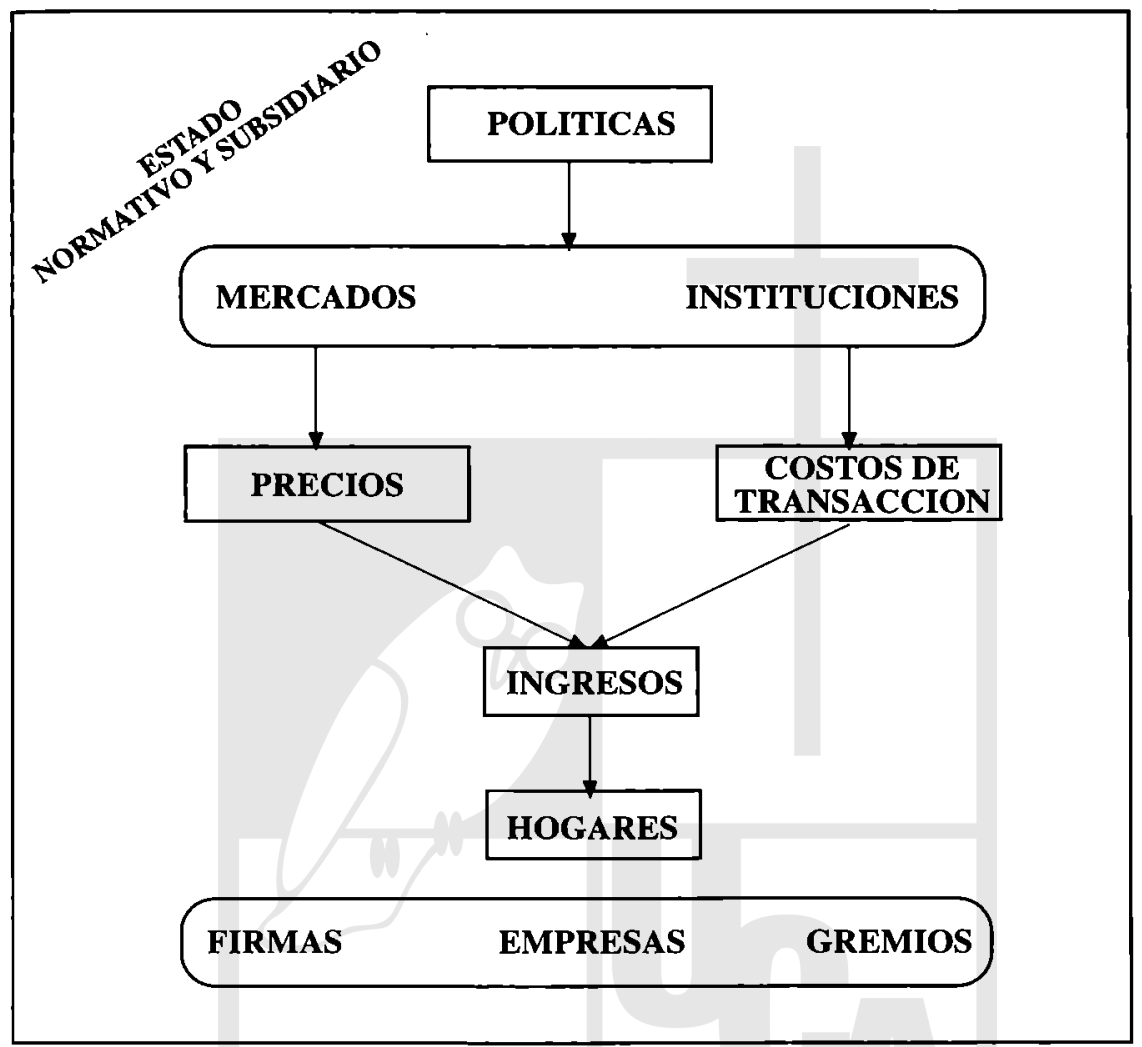

Fuente: Ibid.

En este modelo, el sector agropecuario es considerado como un sistema agroalimentario en donde: "no puede haber producción sin la disponibilidad adecuada y oportuna de insumos y factores; los productos primarios no podrían ser económicamente utilizado sin un conveniente procesamiento e industrialización (utilidad de forma); estos productos, a su vez, no llegarían a los consumidores sin un engranaje de comercialización (utilidades de lugar tiempo y posesión); y, finalmente, los consumidores no podrían adquirir estos productos sin un ingreso suficiente". 
Como economía abierta, esta cadena agro-alimentaria debe estar sostenida en una política comercial que permita una relación justa y leal en lo referente a las exportaciones e importaciones y que, además, incentive y facilite el comercio externo de modo que el país pueda descubrir sus ventajas comparativas y "aprovecharlas para su crecimiento desarrollo y balance alimentario".

Las políticas económicas, según el enfoque pragmático, deben adecuar un entorno institucional para que las estructuras de mercado competitivas dinamicen ese sistema agroalimentario, de manera que prevalezca la rentabilidad y la eficiencia, con unos precios fijados por la oferta y la demanda en un entorno institucional (los hábitos y usos culturales, la posición social y el poder económico de los agentes y las reglas de la negociación) en donde los costos de transacción se encuentren óptimamente minimizados.

No hace falta tratar de demostrar que el llamado "enfoque o modelo pragmático", es el tan publicitado neoliberalismo que el gobierno viene definiendo de forma muy general en sus programas y propuestas de programas desde la administración de Cristiani; cierto es que aquí se presenta más elaborado teóricamente. El gobierno actual a pesar de sus cambios en algunas de sus medidas con respecto a la administración anterior, se encuentra animado por el "pragmatismo", léase neoliberalismo, de este enfoque.

Considerando esa situación, se vuelve fundamental no sólo plantear cuáles fueron las medidas o acciones de política económica que estableció el gobierno anterior, la administración Cristiani, sino también reseñar los mecanismos de política económica que el gobierno recién instalado de Calderón Sol pretende impulsar, para alcanzar los gruesos objetivos que prácticamente son los mismos para las dos administraciones.

El objetivo más general de la política económica de las dos administraciones es, según declaraciones oficiales, "alcanzar el bienestar de todos los salvadoreños en especial los más pobres de los pobres". En relación a los objetivos específicos al sub-sector de los granos básicos, es posible afirmar que se ha dado un cambio sustancial, tal cosa se puede deducir al comparar los planteamientos expresados en la Nueva Política de Granos Básicos (NPGB) impulsada por la administración Cristiani, y las actuales medidas de políticas del nuevo gobierno y lo que se espera lograr.

En la NPGB el gobierno anterior estableció tres objetivos fundamentales:

1) Evitar precios muy bajos en época de cosecha para los productores y alzas muy pronunciadas en épocas de escasez a nivel del consumidor.

2) Fomentar la producción en forma eficiente de manera que sea competitiva internacionalmente, mejorando los ingresos de las familias rurales [el subrayado es nuestro. M. M.]. 
3) Disminuir el costo fiscal ocasionado por las operaciones estatales de comercialización y almacenamiento ${ }^{4}$.

Entre las medidas más importantes con las cuales el gobierno pretendía alcanzar estos objetivos, podemos citar:

1) El desmantelamiento y privatización (venta de activos) del Instituto Regulador de Abastecimiento (IRA).

2) El establecimiento de una banda de precios para determinar los aranceles de importación del maíz, sorgo y arroz.

3) Establecimiento de líneas de crédito (con criterios de mercado) para comercialización interna y externa de granos.

4) Fortalecimiento de programas de investigación y extensión agrícola.

5) Establecimiento de un sistema de información comercial al servicio de los productores y consumidores ("inteligencia de mercado")

La mayor parte de estas medidas se encuentran fuertemente limitadas, en relación a la magnitud de beneficiados que podía generar, por la reducida disposición de recursos y la propia lógica del "novedoso enfoque pragmático", que pretende impulsar su programa en base a criterios competitivos de mercado. Por otra parte, antes de finalizar el período de la administración Cristiani (1993), la banda de precios fue eliminada y, por lo tanto, perdió vigencia el objetivo de evitar precios muy bajos a los productores, aunque en lo relativo a evitar los precios altos para los consumidores, los mecanismos de reserva e importación de granos del gobierno se siguieron manteniendo.

¿Cuál es el papel que en el presente, bajo una nueva administración, se le asigna a la NPGB? Esta cuestión sólo puede ser disipada a través del análisis de los objetivos de política que la administración de Calderón Sol pretende alcanzar. De nuevo, son los asesores/consultores del gobierno que vienen en nuestro auxilio; esta vez es la Oficina de Análisis de Políticas Agrarias (OAPA) del MAG la que publica un trabajo de un grupo de autores encabezados por Hugo Ramos y donde también se agradecen las influencias de Cornelios Hugo (ambos, como se recordará, propositores del "enfoque pragmático"), el cual se titula "Plan económico de El Salvador 1995-1999: Análisis de sus efectos en el sector agropecuario" (abril 1995); en este trabajo los autores enumeran de manera concisa "los objetivos esenciales", estos son:

1) Mejorar la posición competitiva de las industrias y servicios del país.

2) Aumentar la productividad en la producción, especialmente la productividad del individuo, es decir del recurso humano.

3) Mejorar la distribución del ingreso.

4) Reducir la pobreza ${ }^{6}$. 
Al considerar lo que ellos llaman componentes del plan, se puede determinar que varios de esos mecanismos ya se han puestos en marcha, incluso el relacionado al IVA que en ese momento se planteaba incrementar del $10 \%$ al $12 \%$ y que los autores, asumiendo una posición optimista o precavida para adjurar el efecto expectativas, aseguraron que había sido suspendida, entró en vigencia el mes de junio pero no al 12 sino al $13 \%$. En estos componentes no se habla de ninguna política especial para granos básicos, todas las medidas están dirigidas a afectar a la generalidad de los sectores. La privatización, la liberalización de los mercados y el comercio exterior (reducción paulatina de los aranceles a los bienes finales y a los insumos, sistema de libre convertibilidad, etc.), la adecuación del entorno institucional, la modernización del Estado y el aseguramiento de sus ingresos ("los ingresos del Soberano"), son en resumidas cuentas las principales medidas que se mencionan.

Ahora bien, cuando observamos los resultados que se esperan obtener con esas medidas de carácter arancelario, cambiario, fiscal y monetarias, en lo que toca a la producción agropecuaria y, particularmente, de granos básicos; aparece con plena claridad que la NPGB ha sido sustituida por una política de reconversión del subsector de granos básicos, que en términos sencillos significa la eliminación o el desplazamiento de la amplia mayoría de los pequeños productores de granos básicos y su transformación en mano de obra asalariada, el mantenimiento de la producción de granos básico tecnificada y rentable, y, donde debe desaparecer, su sustitución por la industria o agroindustria para la exportación no tradicional o las actividades de ensamblaje; estos, obviamente, deben absorber a los agricultores desplazados; en este proceso de reconversión, como se puede deducir de lo que se acaba de expresar, los agentes serán el capital extranjero y nacional. Pero oigámoslos en sus propias palabras:

El Salvador es un país densamente poblado, con una superficie y recursos naturales limitados, pero con una dotación de mano de obra relativamente abundante. El programa pretende intensificar el uso de la mano de obra en manufactura, industria y actividades de ensamblaje (maquila), convirtiendo al país en una zona franca [sic]. (OAPA, MAG. Plan económico... Ibid. P. 7).

Para evitar cualquier malentendido en cuanto a lo que llaman "mano de obra relativamente abundante", enfatizan a pie de página:

La consideración de que El Salvador es un país agrícola ha sido severamente cuestionada. En realidad, quedan pocas actividades en el sector agropecuario tradicional en las que el país pudiese ser competitivo en el corto plazo para basar en ellas su liberación de la pobreza y su desarrollo. Actividades como el cultivo de arroz, maíz, sorgo y la ganadería de carne, por ejemplo, requieren normalmente un uso extensivo de la tierra, el recurso que precisamente es escaso en El Salvador. Existen oportunidades rentables 
y competitivas en productos de exportación no tradicional que hay que descubrirlas y desarrollarlas con el apoyo de adecuada infraestructura vial, de riego y de servicios como de energía, salubridad y comunicaciones. (Op. cit.).

Teniendo presente que el cultivo de maíz es el principal grano básico que produce el pequeño agricultor salvadoreño, es sintomático que nuestros analistas gubernamentales lleguen a las siguientes conclusiones, sobre el comportamiento de la producción de este rubro y las perspectivas que tienen los agricultores ante la implementación del plan económico:

La estructura de costos de un productor típico, o promedio, y los datos del análisis muestran que la producción nacional del maíz blanco no es competitiva frente a importaciones del producto, bajo el escenario actual y los del plan económico. Es posible que los productores más eficientes e innovadores puedan ser competitivos, pero los productores con tecnologías tradicionales no podrán competir con las importaciones. (OAPA, MAG. Plan económico... Ibid. P. 34).

Ese "no podrán competir" se refiere al desplazamiento de los pequeños agricultores, a la conversión de éstos, y es el único significado que este término parece tener para los más de 240,000 pequeños productores, en mano de obra asalariada, principalmente del capital extranjero; pero si el proceso de conversión, léase proletarización, se va hallar o no sincronizado con las inversiones del capital extranjero y nacional, eso nadie lo puede saber con exactitud, sólo la "mano invisible". Es aleccionador, en esta dirección, las expresiones siguientes del equipo de investigadores encabezados por H. Ramos:

El programa espera que la inversión extranjera fluya rápidamente al país en volúmenes cuantiosos, capaz de absorber la mano de obra que se desplazará del sector tradicional agropecuario. El ambiente macroeconómico generado por el programa, las obras de infraestructura básica y las medidas de seguridad que se ejecutarán [i¿?!] serán suficiente estímulo para atraer la inversión, tanto nacional como extranjera. (OAPA, MAG. Plan económico... Ibid. P. 7).

Todo lo que aquí hemos expuesto, debe ser suficiente para darnos cuenta cuál es el rumbo que ha tomado lo que en un inicio se llamó la Nueva Política de Granos Básicos, y cómo se pretende alcanzar el objetivo 2, relativo al mejoramiento de los ingresos y el nivel de vida de las familias rurales, a través de la conversión de los pequeños productores en trabajadores asalariados, especialmente maquileros.

Si este es el entorno conceptual de la política económica "pragmática" ¿de qué manera han incidido las medidas económicas en el sub-sector de granos básicos y, específicamente, cómo se evidencia ese impacto en las dos micro- 
regiones en estudio? Precisamente acerca de la respuesta a esta interrogante, tratará el tema del siguiente apartado.

\section{A.2. El impacto de las politicas económicas en los ingresos de las micro- regiones}

Al momento de la realización de la encuesta (noviembre, 1994) se puede decir, por razones obvias, que era imposible detectar los efectos del nuevo plan económico del gobierno de Calderón Sol. No obstante, en términos generales, las medidas de política económica del presente gobierno son una continuidad, con algunas diferencias que ya señalaremos, de las acciones iniciadas por la administración Cristiani. Por lo tanto, el impacto que la política económica de Calderón Sol pueda tener sobre los pequeños productores agropecuarios, de alguna manera puede deducirse de lo que ya está ocurriendo como resultado de la política impulsada por Cristiani, de este modo trataremos de evitar al máximo suponer posibles resultados apoyados solamente en las interacciones de las variables, sin recurrir a la realidad que empezó a sufrir cambios como resultado de las políticas neoliberales que inicialmente fueron aplicadas por la primera administración del partido ARENA.

Vamos a citar las medidas de política económica que el gobierno de Calderón Sol ya comenzó a implementar y, al mismo tiempo, se hará referencia a la forma en que cada medida se presentó con la administración Cristiani; así las cosas, las medidas del plan del actual gobierno son las siguientes:

1) Implementación de un sistema de libre convertibilidad de la moneda, a un tipo de cambio anclado en un valor de 8.75 colones por dólar americano. En la administración anterior este sistema se definió como flexible, pero realmente funcionó como uno de flotación "sucia".

2) Ejecución de un programa de desgravación arancelaria que pretende llevar a término la liberalización del comercio externo iniciada en la administración anterior.

3) Aumento del IVA al 13\%; inicialmente se vaciló en la idea de elevar este impuesto hasta el $12 \%$, dejando en suspenso la medida por un tiempo; finalmente fue implementada con un incremento de tres puntos en vez de dos.

4) Reducción de las tasas de interés para estimular la inversión generar empleo y aumentar las exportaciones (esto se espera que sea el resultado del sistema de libre convertibilidad). Las tasas de interés sufrieron aumentos con las políticas de Cristiani, aunque ya era una necesidad para esta administración su reducción, debido a que se quería frenar el flujo de capitales especulativos.

5) Privatización de las empresas y de los activos del Estado con el fin de reducir el déficit fiscal, financiar programas de ayuda durante el período de 
ajuste y, luego, programas de acción en las siguientes áreas: educación, salud, infraestructura y seguridad.

6) Modernización del Estado (reducción de burocracia, adecuación de instituciones, mejoramiento de la recaudación, etc.).

7) Reforzamiento de la seguridad personal y la propiedad ${ }^{7}$.

Como puede verse, aparte de las modificaciones en las medidas financieras relacionadas con la tasa de cambio y las tasas de interés, prácticamente el plan de políticas económicas de Calderón Sol puede ser considerado como la continuidad de las políticas del gobierno anterior. Es la profundización en todas las áreas de las medidas "pragmáticas" de corte neoliberal inspirada en los tres preceptos fundamentales: privatización, liberalización de la economía e influencia del Estado como normador y protector de la libre competencia.

En lo que atañe al sub-sector de granos básicos, el paquete de medidas que se ha citado no deja lugar a dudas que, como parte de la agricultura tradicional, la disyuntiva que se le presenta es: o se vuelve competitivo o desaparece, permitiendo, de ocurrir esto último, la transformación de los pequeño productores en mano de obra asalariada. Estas alternativas se les han ido presentando a los agricultores por medio del impacto en los niveles de ingresos netos, y se puede evidenciar a través de la situación que presentan los siguientes parámetros:

1) Los precios.

2) La capacidad de compra.

3) El consumo.

4) El acceso al crédito.

5) Las condiciones de producción.

6) Las condiciones de la comercialización.

Analizaremos la forma en que se presentan estos impactos, a nivel de las dos micro-regiones sometidas a investigación:

\section{A.2.1. El efecto sobre los precios nominales.}

Para poder determinar cual ha sido la situación de los precios nominales nos va a ser de mucha utilidad considerar las diferenciaciones de precios que se observan entre los distintos tipos de productores y entre los dos municipios, además se hará uso de una encuesta anterior en la cual se recoge la información sobre precios del ciclo 93/94, lo cual nos puede dar una aproximación de la evolución de los precios.

A nivel nacional la situación de los precios promedios (ponderados con los coeficientes de estacionalidad) han presentado una dinámica de crecimiento con 
tasas que se muestran en declive; sin embargo, los precios han tendido a crecer de manera cíclica; desde el año agrícola 88/89 hasta el periodo 91/92 los precios promedios se mantuvieron creciendo aunque lentamente para caer en el año agrícola 92/93, en los años que han seguido hasta el ciclo 94/95 los precios de nuevo han empezado una recuperación lenta. Estas fluctuaciones son las causantes de que las tasas de crecimiento de los precios nominales presenten una débil dinámica, de acuerdo con las apreciaciones del gobierno, tal comportamiento de los precios nominales ha sido uno de los resultados del mecanismo de la banda de precios; un "éxito" cuando es observado del lado del consumidor, del lado del productor supone el incremento de las dificultades para mantener su nivel de vida.

En lo que corresponde a la situación micro-regional, se puede comprobar, según el cuadro siguiente, que los precios nominales de los dos municipios estudiados, se han encontrado en promedio más altos tanto para 1993 como para 1994 para los casos del maíz, el sorgo y el arroz; sólo en lo que respecta al frijol dichos precios se hallan por debajo; sin embargo, cuando se analizan las tasas de crecimiento de los precios se observa que, a excepción del arroz, todos los precios de los granos básicos de la micro-región tuvieron menores tasas de crecimiento que las de los precios promedios nacionales, algunas tasas incluso son negativas. El análisis de estos datos, simplemente evidencia que el efecto de la política económica a nivel nacional con respecto a los precios tiende a reproducirse en las micro-regiones, de modo que, sin temor a equivocarnos, podemos asegurar que la débil dinámica de los precios nominales, generado por el mecanismo estabilizador de la banda de precios, se ha hecho presente de modo más pronunciado en Tecoluca y en San Juan Opico.

\section{CUADRO 1}

COMPORTAMIENTO DE PRECIOS DE LOS GRANOS BASICOS (NACIONAL Y MICRO-REGIONAL)

\begin{tabular}{|l|r|r|r|r|r|r|r|r|r|r|r|r|}
\hline PRODUCT. & \multicolumn{3}{|c|}{ MAIZ } & \multicolumn{3}{|c|}{ FRIJOL } & \multicolumn{3}{c|}{ SORGO } & \multicolumn{3}{c|}{ ARROZ } \\
\hline ANNOS & 1993194 & $1994 / 95$ & TA. CRE & 199394 & $1994 / 95$ & TA. CRE & $1993 / 94$ & 1994195 & TA. CRE. & 1993194 & 199495 & TA. CRE. \\
\hline NACIONAL & 64.95 & 94.15 & $44.96 \%$ & 355.15 & 335.65 & $-5.49 \%$ & 61.15 & 66.88 & $9.37 \%$ & 69.41 & 86.02 & $23.93 \%$ \\
\hline MICRO-REG & 92.88 & 95.93 & $3.28 \%$ & 340.15 & 237.16 & $-30.28 \%$ & 67.00 & 70.42 & $5.10 \%$ & 65.83 & 97.50 & $48.11 \%$ \\
\hline TECOLUCA & 109.02 & 100.00 & $-8.28 \%$ & 332.33 & 245.00 & $-26.28 \%$ & 89.50 & 70.00 & $-21.79 \%$ & 55.00 & 75.00 & $36.36 \%$ \\
\hline S. J. OPICO & 81.53 & 91.85 & $12.66 \%$ & 344.85 & 229.31 & $-33.50 \%$ & 61.38 & 70.83 & $15.41 \%$ & 87.50 & 120.00 & $37.14 \%$ \\
\hline
\end{tabular}

Fuente: Encuesta de ingresos y gastos..., Ibid. Informe de coyuntura, octubre, 1994.

Observando los precios en cada municipio, se puede ver que algunos niveles de precios son más bajos que los promedios nacionales, otros, por el contrario, son más altos. Pero en todos los casos las tasas de crecimiento de los precios en 
los dos municipios son inferiores a las nacionales; excepto en el sorgo (caso S. J. Opico) y en el arroz.

De acuerdo con el análisis sobre los impactos del plan económico del nuevo gobierno que citamos anteriormente, la tasa de protección efectiva del maíz (sistema tecnificado) se calcula para 1994/95 del 7.19\%; esta tasa fue calculada suponiendo que el IVA se mantenía en $10 \%^{8}$, sin embargo, como ya antes consignamos este impuesto se incrementó al $13 \%$, tal impuesto por cuanto afecta a los insumos mas no a los productos, tiende a hacer mucho menos competitivos a los productores nacionales, quienes por el efecto del costo se ven en la necesidad de aumentar el precio, situación que no ocurre con los bienes importados; este aumento del IVA, por lo tanto, suponiendo lo demás constante, tendería a reducir la TPE aproximadamente en 2 puntos porcentuales. Además, debemos mencionar que los estudios nacionales, hasta 1991, determinaron que la tasa de protección efectiva del maíz era negativa, tal situación se atribuyó en ese entonces a la prohibición de exportación que pesaba sobre este cultivo"; lo que nos ilustra bastante bien de lo sensible que es este sub-sector a los cambios de variables que influyen en su capacidad competitiva.

En consecuencia con las políticas promotoras de la libre competencia, y como una evidente muestra de la espontaneidad de las economías entregadas al vaivén de las fuerzas del mercado, en julio de 1995 fue inaugurada la Bolsa de Productos de El Salvador (BOLPROES), la cual funciona como una socjedad anónima creada, según sus propios promotores, para facilitar la compra y venta de los productos agropecuarios. "La finalidad es favorecer la correcta formación de los precios y garantizar la seguridad de las transacciones entre los compradores, comerciantes, industriales y demás entes que participan en la cadena de comercialización"10. Animados por una firme confianza en la virtud de la armonía automática de los mecanismos de mercado, BOLPROES aseguró lo siguiente a los agricultores: "El productor puede estar tranquilo porque va a tener un precio justo de mercado, según la oferta y la demanda. Ser. del mercado quien fijará el precio"'l.

Los "precios justos" que este sistema de transacciones transparente, ha traído a los productores de granos básicos marginados de la asistencia técnica, del financiamiento y atomizados por una política de tierras individualizadora; se encuentran por debajo no sólo de los precios a nivel de finca sino aun para los precios de los transportistas y mayoristas. Por ejemplo, a principios de septiembre de este año (1995) BOLPROES informaba que dentro de las jornadas de trabajo lo más destacado seguía siendo "el precio atractivo del maíz blanco, de 72 colones el quintal, en comparación a los 80 ó 75 colones que se piden por quintal a nivel de mayoristas en las diferentes plazas del país"'2. Si se compara esta situación de precios con los que hemos citado para las micro-regiones, se comprenderá los problemas que nuestros productores del estudio deben estar 
pasando con estos precios tan "justos".

Es obvio que este depresivo comportamiento de los precios, no es responsabilidad única de estos eficientes mecanismos de "inteligencia de mercado", contribuyen también en ello la combinación de las políticas arancelarias, cambiarias y fiscales a las que se hizo referencia arriba; las que, por un lado, favorecen la introducción de productos importados con precios más competitivos, en un contexto en el que los productores nacionales se encuentran sufriendo por los aumentos en los precios de los insumos y los bienes de consumo como consecuencia de la inflación.

Esto último que se ha expresado lo corrobora la Dirección General de Estadísticas Agropecuarias (DGEA) del MAG, cuando refiriéndose, en septiembre de los corrientes, a las condiciones de mercado en San Vicente (en donde se ubica el municipio de Tecoluca) afirmaba: "Los precios del maíz en las distintas plazas experimentaron una baja respecto a la semana anterior..." -luego continúan: "La mayor disminución ocurrió en San Vicente, donde el precio tuvo una rebaja de 9 colones. En semanas anteriores, ese departamento fue el que mayor incrementos de precios registró". Según el informe de la DGEA, la oferta de este producto fue abundante "ya que los volúmenes de maíz nacional e importado que llegaron a la plaza de San Salvador fueron considerables"13.

Aunque estos son comportamientos de corto plazo, no dejan de ser una prueba fehaciente de la tendencia bajista de los precios de los granos básicos, especialmente del maíz ${ }^{14}$.

Con lo que se ha expresado no se intenta decir que los mecanismo de mercado en si sean los causantes de los problemas de los productores, simplemente se busca dejar sentado los hechos en función de evaluar las políticas en su carácter integral. En los siguientes sub-acápites volveremos a tocar los temas relativos a la política arancelaria y cambiaria.

\section{A.2.2. La capacidad de compra y la política económica}

Por lo visto los consultores/asesores del gobierno, a pesar de su enfoque pragmático, se hallan al tanto de la imposibilidad de los productores de granos básicos para hacer frente a un acelerado programa de reducción arancelaria; de modo que a efecto de "preservar" a los productores tradicionales del sector agropecuario nacional de los efectos "indeseables" de las políticas comerciales de desgravación arancelaria, han propuesto un programa con características de gradualidad. Sin embargo, esta misma propuesta que busca llevar los aranceles a las importaciones de los productos finales del 15 a un $6 \%$ en sólo 4 años; ya se muestra bastante acelerada como lo pudimos comprobar en el tema anterior.

En opinión de los propositores de este plan, se vuelve importantísimo ir 
reduciendo las tarifas arancelarias debido a que "la protección ha constituido un mecanismo de redistribución del ingreso por el cual los consumidores han transferido ingresos a los productores..."15; esto puede ser plenamente cierto en el caso de los industriales, pero difícilmente se comprueba en lo relativo a los agricultores de granos básicos y a los pequeños productores agropecuarios en general.

Si se relacionan los datos que tenemos acerca de los precios, los costos de una canasta de insumos y los rendimientos, podremos comprobar lo poco pragmático de referirse a una transferencia de otros sectores a los productores de granos básicos.

El valor de la canasta de insumos promedios de las dos micro-regiones para el caso del maíz, que usaremos de ejemplo por su importancia, en el año de $1993 / 94$ fue de 1,250 colones por manzana ${ }^{16}$, mientras que como apuntamos en el cuadro 3.1 el precio promedio constatado para el mismo ciclo en las dos micro-regiones fue de 92.88 por quintal; por lo tanto, se necesitaban $13.5 \mathrm{qq}$ para adquirir la canasta de insumos necesarios para poder producir; para el ciclo 94/95, el precio promedio del quintal del maíz fue de 95.93 colones y el valor de la canasta de insumos ascendió a 1,138.78; por lo tanto en este año agrícola el productor necesitaba sólo 11.9 qq para obtener la canasta de bienes de producción; aparentemente una mejoría, incluso si se tomase el valor de la canasta del primer ciclo agrícola para calcular la capacidad de compra de los dos años, pero al momento de observar estos datos en relación con los rendimientos, se demuestra que si en el período 93/94 era necesario hacer uso del $27 \%$ del rendimiento para adquirir la mencionada canasta de bienes de producción, para el ciclo $94 / 95$ ese porcentaje había aumentado al $41 \%$, mostrando por lo tanto un deterioro de la capacidad productiva del agricultor y de su nivel de vida.

Este comportamiento también se presenta a nivel de todo el sub-sector de granos básicos del país, por ejemplo se ha determinado, ciclo 94/95, que se necesita un $61.12 \%$ del rendimiento del maíz $(22.4 \mathrm{qq} / \mathrm{mz})$, para poder comprar la canasta de insumos agrícolas; conviene advertir que ese es un poco más del porcentaje que se necesitaba en el ciclo 92/93 para adquirir no sólo la canasta de bienes de producción, sino también la canasta de bienes de consumo, esto es importante enfatizarlo por cuanto si bien en el ciclo 94/95 se observa una mejoría en la capacidad de compra, tal situación al momento de compararla con el rendimiento se comprueba que es aparente. Este deterioro de la economía del productor de granos básicos también se puede observar en relación al ciclo 93/94.

Pero esa situación no sólo tiene que ver con los niveles de eficiencia del productor, también se encuentra vinculada a la débil dinámica de los precios nominales, si éstos no aumentan los suficiente con respecto a los precios de los insumos que comúnmente se han venido utilizando, el agricultor varía la calidad de sus bienes de producción, máxime cuando ésta se relaciona con los precios, 
de modo que el gasto en sus insumos se reduzca; así la canasta para el ciclo 94/ 95 aunque se compone con las mismas cantidades de herbicidas e insecticidas, se diferencian en las calidades; eso obviamente debe incidir en el rendimiento, reflejándonos los resultados que se han señalado (la sequía también ha sido un factor aunque no descalifica este análisis).

El pequeño productor de granos básicos no está preparado aún para hacer frente a la desgravación arancelaria que proponen los consultores del gobierno, mucho menos a una más acelerada; si semejante situación no se toma en cuenta sólo porque existe preocupación en cuanto al "excedente del consumidor", y se decide echar a andar ese proceso con esa velocidad, cuando todavía las dificultades de una economía, como ellos llaman, sticky prices (con precios rígidos: oligopolios industriales, financieros, etc.) no han sido salvados y el gobierno por otro lado avanza lentamente en esta dirección; lo más probable es que los productores desplazados del sub-sector de granos básicos y del sector agropecuario, en general, no podrán ser absorbidos por inversión alguna, a causa de la rapidez con que se desplazarán por el ahogo de sus débiles precios de venta, por los precios de los insumos, el crédito y el alquiler de la tierra y el equipo.

En lo que respecta al "excedente del consumidor", es necesario tomar con calma los planteamientos que sobre el mismo se pueden hacer, el solo análisis de la capacidad de compra con el rendimiento nos hacen dudar de las llamadas transferencias de ingresos de los consumidores a los productores de granos básicos; sin embargo, no lo podemos descartar a priori. Para poder salir de dudas se vuelve necesario ver al productor también como consumidor; eso lo abordaremos en el siguiente acápite.

\section{A.2.3. El consumo de los productores}

Si analizamos los datos de los niveles de consumo alimenticio de los pequeños productores de las micro-regiones que se han estudiado en relación con los cálculos oficiales del MIPLAN, en los cuales la línea de pobreza absoluta para 1994 se encontraba definida por una canasta alimenticia cuyo costo era de $\varnothing$ 847.15 , mientras que la línea de pobreza relativa se definía como el doble de aquélla, se puede determinar, de acuerdo al cuadro 2, que en términos generales los productores de San Juan Opico y los de Tecoluca se encuentran un $18.4 \%$ y $14.9 \%$, respectivamente, sobre la línea de pobreza absoluta; no obstante, si se analiza los productores por separado, se puede constatar que sólo los arrendatarios, los propietarios (especialmente en S. J. Opico) y los de la R.A. individual se encuentran considerablemente sobre la nivel oficial de pobreza absoluta; los demás o se hallan por debajo o ligeramente encima.

Si ahora observamos cuál es la situación en cuanto al límite oficial para definir la pobreza relativa, nos daremos cuenta, de acuerdo al mismo cuadro, que los productores de ambos municipios se encuentran en condiciones de po- 
breza relativa, aun así los porcentajes se acercan al límite oficial, situación que, de nuevo, es determinada por únicamente tres tipos de productores: los arrendatarios, los propietarios y los de la R.A. individual.

\section{CUADRO 2}

\section{POBREZA ABSOLUTA Y RELATIVA EN TECOLUCA CICLO 94/95}

\begin{tabular}{|l|c|c|c|c|c|c|c|c|c|}
\hline MUN.JPRO. & ARRENDAT. & ASALARIAD. & DESMOVIL. & COLONO & TENED. & PROPIET. & R.A. COLEC. & R.A. INDIVID. & TOTAL \\
\hline ABSOLUTA & & & & & & & & & \\
\hline S. J. OPICO & $123.6 \%$ & $81.1 \%$ & $0.0 \%$ & $108.0 \%$ & $0.0 \%$ & $110.1 \%$ & $0.0 \%$ & $1405 \%$ & $118.4 \%$ \\
\hline TECOLUCA & $123.6 \%$ & $0.0 \%$ & $82.6 \%$ & $0.0 \%$ & $56.4 \%$ & $91.6 \%$ & $96.9 \%$ & $158.1 \%$ & $114.9 \%$ \\
\hline RELATIVA & & & & & & & & & \\
\hline S. J. OPICO & $75.2 \%$ & $45.5 \%$ & $0.0 \%$ & $54.6 \%$ & $0.0 \%$ & $76.0 \%$ & $0.0 \%$ & $95.2 \%$ & $77.7 \%$ \\
\hline TECOLUCA & $100.6 \%$ & $0.0 \%$ & $49.4 \%$ & $0.0 \%$ & $46.1 \%$ & $64.5 \%$ & $56.4 \%$ & $98.0 \%$ & $80.7 \%$ \\
\hline
\end{tabular}

Fuente: Ingresos y gastos..., Ibid. y MIPLAN, 1995. Los porcentajes se obtuvieron dividiendo el gasto promedio mensual en alimentos por estrato entre el valor oficial (MIPLAN) de la canasta alimenticia nutricional que era igual para el período $94 / 95$ a $\$ 847.15^{17}$.

Esta estratificación de los pequeños productores agrícolas o campesinos pobres no debe confundirnos, antes bien, debe llevarnos a reconocer dos cosas fundamentales:

1) Los pequeños productores agropecuarios se encuentran por debajo o en el umbral (cuando la situación es mejor) de la pobreza absoluta y, a su vez, sufren la pobreza relativa definidas oficialmente.

2) Los campesinos pobres no sólo se encuentran al margen de las ventajas que pueda generar el desarrollo económico; sino también, dada la artificialidad de los parámetros oficiales para definir la pobreza, la negación de la propia existencia como seres humanos.

$\mathrm{Si}$ observamos el promedio total de los gastos de bienes de consumo de los pequeños productores agropecuarios (que incluye, además de alimentos, vivienda, salud, educación, vestuario y transporte), podremos darnos cuenta que, varios de los agricultores se encontrarían por encima del límite de la pobreza absoluta aunque siempre experimentarían pobreza relativa; sin embargo, los niveles alimenticios se hallan por debajo de los nutricionalmente necesarios, lo cual en realidad es pobreza absoluta. Podría argüirse que cuando se tiene el ingreso suficiente para evitar padecer de pobreza absoluta, sólo el "irracional" uso de los ingresos puede explicar su existencia; no obstante, es difícil imaginar cómo podría pasársela un ser humano sin poseer un techo bajo el cual pueda 
protegerse de las inclemencias del tiempo, sin vestirse, estudiar, transportarse y cubrir sus gastos mínimos para el mantenimiento de la salud. Honestamente, es imposible que alguien que desde el punto de vista del ingreso se encuentre en el umbral de la pobreza absoluta, lo vaya a gastar todo sólo en alimentos, al contrario, intentará gastar el mínimo en otros artículos no alimenticios, comprimiendo aquéllos, pero también fundamentales y en ese afán se verá sometido al sufrimiento tanto de la pobreza absoluta como de la relativa. Eso es precisamente lo que se ha podido detectar en las dos micro-regiones en estudio. Estas condiciones también han podido ser corroboradas a nivel del sub-sector del país ${ }^{18}$.

En cuanto al segundo aspecto, se puede decir que no existe una sólida razón por la cual los límites oficiales de la pobreza absoluta no sean en verdad los límite de la deshumanización absoluta, pues debe recordarse que hasta en la crianza de animales se establece un nivel mínimo nutricional, con lo cual, hablar del límite de la pobreza absoluta es sólo una forma "educada" para referirse a aquel punto crítico en el que las personas dejan de serlo para convertirse en seres que trabajan exclusivamente para comer, y para quienes es ajeno el goce del excedente que su actividad genera; es una situación en la que el hombre se ve obligado a hacer estrictamente lo que los animales hacen: realizar actividades para obtener alimentos, con el agravante de que en el caso de los campesinos pobres, tales actividades deben ser planificadas en el pensamiento con habilidad e inteligencia humana. Ningún ser pensante haría esto de no estar obligado por ciertas condiciones, y semejantes condiciones no pueden existir sin una necesidad objetiva, estructural, y una voluntad de aquellos a quienes beneficia.

Con lo que hemos podido comprobar, no vale la pena referirse a lo que podría ser una aproximación a los gastos de consumo que determina el grado de desarrollo económico que El Salvador presenta, esto es, la canasta alimenticia y la de mercado urbana (IPC); esos niveles de consumo se hallan muy lejos de los constatados en los municipios de nuestra investigación ${ }^{19}$, como efectivamente lo demuestra el cuadro 3.

Con agricultores que se esfuerzan no sólo en actividades agropecuarias, laborando en su parcela, y no agropecuarias, como asalariados, trabajando en su propia casa en el procesamiento de productos, en el comercio, etc.; para obtener a como dé lugar un rendimiento que les permita apenas vegetar, es difícil hacer referencia a la posibilidad de la transferencia hacia ellos de los ingresos de los consumidores a causa de la protección arancelaria; empero, los adeptos de la microeconomía son "serios" y esta ciencia, además, es fría; por lo tanto los asesores del gobierno se han referido a ello como un hecho incuestionable que sustenta la necesidad de la política "gradual" de desgravación arancelaria. 


\section{CUADRO 3}

\section{POBREZA ABSOLUTA Y RELATIVA EN BASE A CANASTA ALIMENTICIA Y DE MERCADO (IPC) EN TECOLUCA Y SAN JUAN OPICO CICLO 94/95}

\begin{tabular}{|l|c|c|c|c|c|c|c|c|c|}
\hline MUN IPRO. & ARRENDAT. & ASALARIAD. & DESMOVIL. & COLONO & TENED. & PROPIET. & R.A. COLEC. & R.A. INDIVID. & TOTAL \\
\hline ABSOLUTA & & & & & & & & & \\
\hline S. J. OPICO & $61.9 \%$ & $40.6 \%$ & $0.0 \%$ & $54.0 \%$ & $0.0 \%$ & $55.1 \%$ & $0.0 \%$ & $70.3 \%$ & $59.2 \%$ \\
\hline TECOLUCA & $61.8 \%$ & $0.0 \%$ & $41.3 \%$ & $0.0 \%$ & $28.2 \%$ & $45.8 \%$ & $485 \%$ & $79.1 \%$ & $57.5 \%$ \\
\hline RELATIVA & & & & & & & & & \\
\hline S.J. OPICO & $34.0 \%$ & $20.6 \%$ & $0.0 \%$ & $24.7 \%$ & $0.0 \%$ & $34.3 \%$ & $0.0 \%$ & $43.0 \%$ & $35.1 \%$ \\
\hline TECOLUCA & $45.5 \%$ & $0.0 \%$ & $223 \%$ & $0.0 \%$ & $20.8 \%$ & $29.1 \%$ & $255 \%$ & $44.3 \%$ & $36.5 \%$ \\
\hline
\end{tabular}

Fuente: Encuesta de ingresos y gastos..., Ibid. y MIPLAN, 1995. El método utilizado es igual al anterior sólo que haciendo uso de los parámetros de la canasta de consumo relativos al IPC 1994/95.

Se ha dicho en este documento, que hablar de la redistribución del ingreso del consumidor a los sectores protegidos es necesario y real en el caso de los empresarios industriales; no es éste el caso del productor de granos básicos, o del pequeño productor agropecuario; para quien, como se pudo demostrar en su momento, existe una transferencia de valor más esencial que se traslada de ellos hacia el sector capitalista; sin embargo, aun viéndolo desde el enfoque microeconómico y de la teoría del comercio internacional (ver anexo A y B, próxima publicación del segundo artículo) se comprueba que este fenómeno no cobra relevancia para la producción de granos básicos.

Se sabe que cuando se establece un arancel se generan dos tipos de pérdidas: la relacionada con el despilfarro de recursos destinados a una producción ineficiente y la pérdida del excendente del consumidor, lo que deja de consumir, a causa de la subida del precio del producto al que se protege con el arancel; la teoría de la economía internacional comprueba que con lo que se ganaría eliminando el arancel, es decir estableciendo el libre comercio, se podría cubrir las pérdidas de aquellos productores que saliesen afectados; esto último parece ser la idea de la política económica pragmática, el gobierno todavía no ha especificado con claridad cómo piensa hacer eso dado que esto sugiere una redistribución de los ingresos ganados por la apertura externa, pues no es automático que quienes son desplazados de las actividades ineficientes se transformen instantáneamente en ganadores o en receptores de esas ganancias; ese vacío es el que se ha venido cuestionando cuando se ha hecho referencia a la "mano invisible". El desconcierto e indefinición, aparte de la retórica, en cuanto a este aspecto, de 
por sí pondría un alto al pretendido proceso gradual de desgravación; tales medidas tocan con la suerte de más o menos el $40 \%$ de la población rural que deberían ser absorbidos, si la inversión nacional y extranjera no crece adecuadamente, sólo por la industria sometida también a la desprotección.

Todavía queda en pie la pérdida del excedente del consumidor; ésta ha sido la preocupación más relevante para los consultores/asesores del gobierno, pues parece que la anterior es bastante evidente cuando en el país ni tan siquiera se resuelve el problema de los desempleados con parte las ganancias de otros derivadas del relativo libre comercio ${ }^{20}$; pero semejante preocupación deja de tener interés si establecemos que, para el caso de los granos básicos, esta mencionada pérdida de excedente del consumidor en realidad no existe; esto podrá parecer sorprendente para los amantes de la economía internacional, para disipar esta sorpresa basta decir que en El Salvador para la mayoría de consumidores de granos básicos, o sea los trabajadores, sus salarios reales se adecúan siempre a una cantidad nutricional de estos bienes, de modo que a medida que se baja el arancel y con ello el precio de los granos, también los salarios reales tienden a ajustarse a esta baja, de esta forma si existe un excedente del consumidor que se pierde, es seguro que esta cantidad es despreciable.

Una aseveración como esta debe escandalizar a los fieles seguidores de la economía instrumental, pero es el resultado de la realidad, debe quedar claro que no es el fin del instrumentalismo económico, simplemente es una más de las distorsiones del capitalismo subdesarrollado; pero obviamente, tal afirmación no puede sencillamente afirmarse sin más, requiere sustentarse con evidencia empírica. En realidad, cabe decir que ha sido el propio comportamiento real el que ha obligado a hacer estas observaciones, acerca de la política arancelaria para el sub-sector de granos básicos.

Un estudio de Joseph Laure relacionado a la capacidad de compra de los salarios mínimos a lo largo de más de 30 años, desde 1954, ha comprobado que los salarios mínimos sólo han permitido la cobertura de unos bienes cuyos precios se han mantenido estables, estos son los granos básicos ${ }^{21}$; este comportamiento también ha sido demostrado para los años comprendidos entre 1989 y 1995, los salarios tienden a cubrir estrictamente la canasta básica alimenticia familiar del MIPLAN, compuesta principalmente con granos básicos. De igual forma, la dinámica de los precios relativos de los granos básicos tiene mucha similitud con el comportamiento de los salarios reales, tanto agropecuarios como urbanos.

Podría pensarse que dado que Laure ha demostrado que los salarios mínimos urbanos se ajustan a los precios de los granos básicos, de modo que el asalariado logre obtener una canasta de alimentos que lo mantenga más o menos en el umbral de la pobreza absoluta, los productores de granos básicos se benefician de ser productores y asalariados a la vez puesto que eso significaría que la 
adquisición de bienes de subsistencia a través de su salario, más lo que obtienen por la venta de sus cultivos, más su autoconsumo debe dar un nivel mayor que el consumo de subsistencia del obrero de la ciudad; tal cosa, aunque parece probable, no ocurre por dos fuertes razones:

1) El salario agropecuario es más bajo que el urbano; y así ha sido a lo largo del tiempo según Laure.

2) El trabajo asalariado agropecuario generalmente es estacional.

Eso es lo que explica que los productores agropecuarios, como se demostró más arriba, se encuentren en el umbral de la pobreza absoluta, al igual que los asalariados urbanos.

Pero hasta aquí no se ha hablado nada del impacto de la política cambiaria y fiscal; vamos a abordarlas considerando los problemas de los pequeños productores en cuanto al crédito, la producción y la comercialización.

\section{A.2.4. El crédito de los productores}

Es bien conocido que con la privatización de la banca, la eliminación de subsidios a los pequeños productores y de las diversas líneas de créditos "blandos" de las cuales se beneficiaban; las tasas de interés real subieron llegando a niveles de ;competitividad!, y las dificultades para obtener créditos por parte de los pequeños agricultores aumentaron severamente. Los recursos financieros ahora se colocan de acuerdo a los parámetros de mercado, la producción de granos básicos y, en general, la pequeña producción agropecuaria no es rentable, por tanto, no son sujetos de créditos. Por otra parte, la banca de fomento del sector agropecuario, también se ajustó a esos criterios.

Ante ese problema y el mencionado arriba sobre los aranceles, el gobierno se había referido, a lo beneficioso de una política cambiaria que buscaba mediante las devaluaciones reducir la sobrevaloración de nuestra moneda y con ello aumentar la competitividad interna de los granos básicos, que se veía mermada por la desgravación arancelaria, y la competitividad externa de los bienes exportables; empero, el componente inflacionario de las devaluaciones vino a echar por tierra estos dos fines, especialmente en lo que respecta a los productores de granos básicos; para éstos, el aumento inflacionario de los precios de los insumos no permitió que sus productos mermaran la caída de la competitividad resultante de la política arancelaria, más bien acentuó este declive.

Estos resultados han suscitado polémicas, para algunos la sobrevaloración de la moneda se mantiene, como resultado del flujo de remesas y capitales cortoplacistas, especulativos; por lo que se debe recurrir a la devaluación para buscar la mencionada competitividad; para otros, especialmente el Departamento de Economía de la UCA, siendo consecuentes con las tan publicitadas medi- 
das que pretenden generar la liberalización de los mercados para permitir que la asignación de recursos se dé como resultado del libre juego de la oferta y la demanda, tal "apreciación del colón" no existe ya que es precisamente el tipo de cambio que el mercado fija ${ }^{22}$.

Finalmente la decisión gubernamental, sesgada hacia las opiniones de la apreciación del colón, fue fijar el tipo de cambio. De acuerdo con el Departamento de Economia, cuando el gobierno y sus consultores/asesores se refieren a la sobrevaloración de la moneda lo hacen del lado de los intereses de los exportadores y de los sectores sustitutivos de importaciones, es una especie de confesión técnica de cuáles son los grupos económicos que influyen principalmente en las decisiones del gobierno. Si el objetivo de la fijación del tipo de cambio no es favorecer al sector productor de transables ${ }^{23}$, el gobierno debe explicar qué es lo que pretende. Hasta ahora, asegura el Departamento, una estrategia que privilegia al sector exportador no ha demostrado impulsar el desarrollo humano productivo, ni de aquellos que no pueden insertarse en el modelo de crecimiento propuesto, como es el caso de la pequeña producción agropecuaria.

Además, continúa el artículo del departamento, estos sectores que la política cambiaria del gobierno está privilegiando no han demostrado ser convenientes en términos de empleo, componente de valor agregado dentro de su producción, integración vertical y horizontal con otros sectores, crecimiento del componente salarial dentro del valor agregado, etc. "Por lo tanto, el apoyo ha sido altamente basado en consideraciones políticas, más que en consideraciones de desarrollo de la infraestructura productiva y social del país"24.

A este respecto debemos, de nuevo, retomar nuestro trabajo; si bien es cierto no es posible ver cuál es la conveniencia de que el gobierno favorezca a los sectores productores de bienes transables; sí se puede establecer con claridad una de las distorsiones esenciales para que estos sectores puedan desenvolverse felizmente, consiste en la existencia de un sector débil y numeroso de pequeños productores agropecuarios que sea "capaz" de facilitar:

1) Mano de obra barata para el empleo estacional y permanente que ofrece el sector de transables.

2) Alimentos, especialmente granos básicos, a bajos precios que permitan mantener reducidos los salarios reales.

3) Insumos a bajos precios, casi siempre afectados por las importaciones.

4) Fuente, aunque precaria, de ingresos para los desempleados estacionales, los que resultan de las fases de crisis y los jubilados o que les han dado de baja a causa de la vejez.

Este interesante fenómeno es una muestra perfectamente ilustrativa de lo que significa el subdesarrollo, un sector transable que se erige (en términos de renta- 
bilidad y eficiencia) sobre la debilidad del subsector de granos básicos y otros productores agropecuarios, pero que cuando se piensa en reconvertir el aparato productivo: industria (incluyendo la de ensamblaje) y agroindustria; estos sectores que se han encontrado expoliados y subordinados (subsumidos) deben cargar con los costos. Por esa razón no es raro, aunque parece poco coherente, que por un lado se intente proteger al sector de transables y desfavorecer a los productores pequeños de granos básicos y de otros productos agropecuarios, al mismo tiempo que se sostienen los intereses nacionales (en especial de los más pobres de los pobres) como objetivo.

Otro de los aspectos que sobre la fijación del tipo de cambio cuestiona el Departamento de Economía de la UCA, consiste en el costo que para el BCR representa dicha medida; mientras la Banca Central obtiene pérdidas considerables como resultado de sus operaciones de monetización del dólar y sus consecuentes acciones de estabilización monetaria, el presupuesto se limita de forma estricta en partidas como educación y salud.

Pero no sólo se limita en ello, se ha dicho, y se ha demostrado a nivel nacional y micro-regional, que la cobertura de créditos a los pequeños proJuctores es insuficiente; empero, los estudios recientes sobre el crédito señalan que existen los recursos necesarios para financiar a los pequeños productores agropecuarios, no obstante, "la prevalencia de condiciones adversas para el acceso de los mismos al financiamiento formal, no permite que el crédito agrícola se convierta en un instrumento de desarrollo que potencie la sostenibilidad de los pobladores rurales" 25 . Los créditos se han estado canalizando a actividades no productivas reduciendo cada vez más la participación agropecuaria; pero, además, dentro de la cartera destinada a este último sector, se muestra una tendencia histórica al financiamiento de la producción tradicional y a la marginación de los pequeños productores ${ }^{26}$. Si a todo esto, agregamos los fondos que se diluyen en la pérdida cambiaria por favorecer al sector de transables, la única explicación que resulta plausible es la de que asistimos al ahogamiento financiero de los pequeños productores agropecuarios, pues obviamente no son las pérdidas las que ahuyentan los dineros del gobierno de los sectores económicos, como bien lo demuestra el rumbo que ha tomado la política cambiaria.

De manera similar al hecho de que los créditos se canalizan a sectores no productivos, la fijación del tipo de cambio es una medida que desdeña la posibilidad de transformar la estructura productiva y social, y elevar por esa vía la competitividad real de los productos transables ${ }^{27}$, dado que se convierte en un subsidio para los sectores que los producen, algo que en el caso de los pequeños productores ha sido eliminado y fuertemente fustigado por los hacedores de política económica del gobierno.

Uno de los defectos fundamentales de la política de créditos por el cual los pequeños productores del país se quejan mucho es el hecho de que la finaliza- 
ción de los plazos de los préstamos que se les otorgan coincide con el período de cosecha de los granos básicos, lo que presiona a los agricultores a vender rápidamente sus productos en el momento en que los precios se encuentran más deprimidos ${ }^{28}$, situación que contribuye en la mayoría de los casos a que incurran en problemas de morosidad.

En el mencionado trabajo sobre el crédito agropecuario se resumen los resultados de las políticas crediticias gubernamentales en las siguientes palabras, con las que finalizamos este tema:

Aun cuando el programa de privatización y modernización de la banca, impulsado con el Programa de Ajuste Estructural, pretendía la democratización del crédito, en la actualidad la exclusión del pequeño productor sigue presente... (Tobar, J. El crédito agropecuario... Ibid. P. 74).

(...) La modernización y privatización del sistema financiero no han afectado en gran medida el funcionamiento de la banca oficial de fomento agropecuario, de tal manera que los problemas prevalecientes en décadas anteriores continúan pendientes y a la espera de soluciones prácticas para hacer de esta instituciones verdaderas propulsoras del desarrollo (Tobar, J. Ibid. P. 75).

\section{A.2.5. Las condiciones técnicas de la producción}

Analizaremos este tema considerando dos aspectos básicos que influyen en la producción, y que se ven influenciados por las condiciones que se experimentan en los ingresos, estos son: la asistencia técnica y el uso de equipos.

En lo concerniente con la asistencia técnica, la información que se conoce indica que el servicio que presta el gobierno sólo cubre al $13 \%$ de los pequeños productores de granos básicos, si, de acuerdo con las investigaciones acerca del crédito, aceptamos que a los pequeños productores se va unir una cantidad de desmovilizados, en el marco de los Acuerdos de Paz, de aproximadamente ${ }^{29}$ 40,000 , el mencionado porcentaje tendería a caer casi al $11 \%$. No hace falta decir aquí que con semejantes ingresos que se han evidenciado a nivel nacional y micro-regional, y que resultan del impacto de las medidas que ya hemos analizado, al productor se le hace absolutamente imposible contratar asistencia técnica privada. En las micro-regiones estudiadas, si bien los niveles de asistencia técnica son más altos que a nivel nacional (16\% en S. J. Opico y $28 \%$ en Tecoluca), no dejan de ser, en general, también proporciones insuficientes como para generar el desarrollo económico de los pequeños productores; esto sin entrar en evaluaciones acerca de la calidad de la asistencia.

Recientemente en una investigación en el municipio de Tecoluca, la mayoría de los productores entrevistados que recibían asistencia técnica sostuvieron que 
uno de los principales obstáculos para poder implementar las innovaciones tecnológicas es su situación económica ${ }^{30}$, lo cual nos revela un círculo vicioso entre la asistencia técnica y la pobreza de los pequeños agricultores, semejante estado de cosas nos deja claro que los problemas de los pequeños productores no sólo son técnicos sino también socioeconómicos.

En lo relativo al uso de equipos y tecnología, los propios asesores/consultores del gobierno sostienen que su uso por los productores pequeños es ínfimo a nivel de todo el país, en cuanto a esto ellos se refieren a la necesidad de generar economías de escala, para lo cual se requiere la organización de los pequeños productores y su capacitación en gestión empresarial, esto último se abordará más adelante en el apartado que tratará de las soluciones. Lo importante resaltar aquí es que para los productores, debilitados en lo relativo a los ingresos y con una cobertura crediticia excesivamente precaria, las posibilidades de usar tecnologías se vuelven remotas, máxime si se considera que el gobierno no está promoviendo principalmente las "economías de escala" en el caso de los favorecidos por la Reforma Agraria ni de los pequeños productores agropecuarios.

Así, pues, las condiciones de la producción, en cuanto a la asistencia técnica y al uso de tecnología, parecen estar fuertemente determinadas por la situación en los ingresos y, por ende, muy influidos por políticas como la arancelaria, la fiscal, la cambiaria y monetaria (principalmente en lo relativo a la tasa de interés) y la de créditos.

\section{A.2.6. Las condiciones de comercialización.}

Para este caso podemos destacar tres factores que son fundamentales: la información, las condiciones de acopio que poseen los productores y el manejo que el gobierno hace de lo que llama "reserva estratégica".

Sobre la información, ya se expuso que mecanismos como el de la bolsa de productos, pueden ser una arma de doble filo; así como puede indicarle al productor un buen precio, de la misma forma puede dar origen a importaciones competitivas que arruinen a los productores; esto podría ser llamado la "lógica del libre mercado, necesaria para la eficiencia" en lugar de arma; no obstante, debe tenerse presente que hay un claro sesgo a que ocurra el último fenómeno, dada las característica de nuestra producción nacional de granos básicos y al ambiente de desgravación arancelaria. Pero tal cosa nos remite al segundo factor: el acopio.

Si el productor tuviese capacidad de acopiar sus granos, de modo que le fuese posible regular la salida de la oferta, la actividad de la bolsa de productos podría traerle grandes beneficios; empero, tanto las investigaciones a nivel de todo el país sobre la infraestructura con que cuenta el pequeño productor, como la encuesta micro-regional demuestran que esa infraestructura está compuesta, 
en el mejor de los casos, principalmente de cercos, barriles y pozos y, en el peor, no posee absolutamente nada, lo que lo hace vulnerable a las depresiones de los precios.

Por cuanto el gobierno debe prever cualquier posibilidad de desabastecimiento alimentario, ha establecido el mecanismo de la "reserva estratégicas" que ha venido evolucionando desde "el viejo estilo de considerarla como el volumen mínimo de granos dentro del país" lo cual "deja de ser válido en el contexto moderno de una economía abierta en el proceso de globalización"; hasta transformarse en el moderno concepto que los asesores del gobierno definen de la siguiente forma:

(...) Más importante que el almacenamiento de granos dentro del país, es ahora asegurar la capacidad de compra de los granos básicos en el mercado mundial. La seguridad alimentaria está en los silos esparcidos en los países altamente productores de granos, los que, gracias a las facilidades de transporte moderno y al libre movimiento de capitales, puede arribar a un país necesitado en el transcurso de pocas semanas. (Ramos, et. al.).

Para el productor de granos básicos nacional, basta decir que esta "reserva estratégicas", tanto en su nueva como en su vieja acepción, simplemente se ha traducido en la depresión de los precios de sus productos como resultado del excesivo abastecimiento en épocas de cosecha; esto ha sido corroborado, para el caso del maíz, por los investigadores de FUSADES ${ }^{3 !}$. A esto se viene a agregar las presiones generadas F r los plazos para cancelar los créditos que generalmente coinciden con los niomentos de salida de la cosecha.

Como puede verse la capacidad de almacenamiento del productor es fundamental en una economía de mercado, en donde las distorsiones de la anarquía productiva o de las políticas erradas, podrían obligar al productor a regular la oferta para poder evitar pérdidas; ese esquema, sin embargo, se encuentra muy lejos de nuestro productor de granos básicos, y de los pequeños productores agropecuarios en general, los cuales no tienen capacidad económica para adecuar o establecer la infraestructura necesaria para la producción y el acopio.

A lo largo de este apartado, se ha demostrado que las políticas económicas que el gobierno ha venido implementando, han tenido efectos reductivos sobre los ingresos reales de los productores de granos básicos, tanto las de carácter macro y microeconómico, que se han traducido en las medidas de naturaleza fiscal, monetario y cambiario; como las de naturaleza comercial, de tierras, sectorial e institucional que se han concretado en, v. gr., las medidas de desgravación arancelaria, atomización de los productores agropecuarios, asistencia técnica, privatización de la banca, etc.

El problema de los insuficientes ingresos reales, hace totalmente imposible que los pequeños productores agropecuarios puedan ser competitivos, y puedan 
iniciar su propio desarrollo económico en un entorno condicionado por los preceptos del "enfoque pragmático" (neoliberal); es, como puede captarse, un verdadero círculo vicioso (y no "virtuoso", según quiere hacerlo creer la retórica gubernamental).

\section{B. Los ingresos y gastos: su influencia en el problema ecológico y en la economía familiar}

El problema ecológico y la economía familiar, son dos aspectos que han adquirido reciente importancia para las Ciencias Económicas. La investigación que se realizó nos arrojó cierta información tanto sobre el problema ecológico como acerca de la economía familiar. Por cuanto los datos son muy elementales, y dada la naturaleza de la investigación, en este trabajo no se ahondará en el tema, sólo se intentará determinar en la medida de posible la manera en que el efecto de las políticas económicas en los ingresos reales de los productores, trasciende hasta influir en las condiciones del medio ambiente y la economía dentro de los hogares campesinos. Dividiremos este apartado en dos acápites, el relativo a la influencia de las políticas en el medio ambiente y el que se encuentra relacionado a la economía familiar.

\section{B.1. El impacto de las políticas económicas en los ingresos y la condiciones del medio ambiente}

En el país no son pocos los investigadores socioeconómicos que han señalado que las condiciones de pobreza, a la que se ven sometidos los campesinos salvadoreños, juegan un papel determinante en la depredación de los recliisos naturales, debido a que en su lucha por la subsistencia que debe librar e! hombre del campo la disyuntiva que se le presenta se resume en: o se deja morir él y su familia para proteger la naturaleza o asegura su vida presente aunque agote recursos y el futuro parezca incierto.

De acuerdo con la información que se obtuvo en San Juan Opico, existe una tendencia que señala que los productores que tienen los más bajos niveles de consumo (los asalariados y los colonos) son los que hacen más uso de la explotación de los recursos naturales; obviamente, el efecto de las políticas económicas en los ingresos, desemboca en que la actividad de los productores en las labores agropecuaria y no agropecuarias sólo alcancen para cubrir unos gastos de consumo que los mantiene en la pobreza absoluta y relativa; por ende, cuanto más grave sea esta situación, tanto más necesaria se hace la explotación de los recursos de la naturaleza. Los datos sobre el uso de los recursos de la naturaleza se resumen en el cuadro siguiente: 
CUADRO 4

S. J. OPICO: USO DE LOS RECURSOS NATURALES POR LOS PEQUEÑOS AGRICULTORES CICLO (94/95)

\begin{tabular}{|l|r|r|r|r|r|r|}
\hline PROPIE. & ARREND. & ASALARIA. & COLONOS & PROPIETA. & R. A. INDIV. & TOTAL \\
\hline UTLIZA & 1 & 2 & 1 & 7 & 6 & 17 \\
\hline PORCENTAJE & $14.29 \%$ & $40.00 \%$ & $50.00 \%$ & $35.00 \%$ & $40.00 \%$ & $34.69 \%$ \\
\hline NO UTLIZA & 6 & 3 & 1 & 13 & 9 & 32 \\
\hline PORCENTAJE & $85.71 \%$ & $60.00 \%$ & $50.00 \%$ & $65.00 \%$ & $60.00 \%$ & $65.31 \%$ \\
\hline TOTAL & 7 & 5 & 2 & 20 & 15 & 49 \\
\hline PORCENTAJE & $14.29 \%$ & $10.20 \%$ & $4.08 \%$ & $40.82 \%$ & $30.61 \%$ & $100.00 \%$ \\
\hline
\end{tabular}

Fuente: Encuesta de ingresos y gastos..., Ibid.

Las actividades de explotación de recursos naturales a las que más se dedican los encuestados son: a la explotación de leña $(26 \%)$ y recolección de frutas (43\%); sin embargo, también juegan un considerable papel la caza (17\%) y la pesca (13\%). Aunque los asalariados y los colonos son los que más han hecho uso de los recursos silvestres, por ejemplo la explotación de leña, son los que menos participan en las actividades de reforestación, esto en parte también se encuentra vinculado a las condiciones materiales en las que se desenvuelven (ver cuadro 5).

\section{CUADRO 5}

S. J. OPICO: PRODUCTORES QUE REFORESTARON O NO.

\begin{tabular}{|l|c|c|c|c|c|c|c|}
\hline & $\begin{array}{c}\text { HA } \\
\text { PROPIT/ACTITUD }\end{array}$ & $\%$ & $\begin{array}{c}\text { NO HA } \\
\text { SEMB. }\end{array}$ & $\%$ & N.R. & $\%$ & TOTAL \\
\hline ARRENDATARIOS & 2 & $25.00 \%$ & 6 & $75.00 \%$ & 0 & $0.00 \%$ & 8 \\
\hline ASALARIADOS & 1 & $20.00 \%$ & 4 & $80.00 \%$ & 0 & $0.00 \%$ & 5 \\
\hline COLONOS & 0 & $0.00 \%$ & 2 & $100.00 \%$ & 0 & $0.00 \%$ & 2 \\
\hline PROPIETARIOS & 10 & $50.00 \%$ & 7 & $35.00 \%$ & 3 & $15.00 \%$ & 20 \\
\hline REF. AGR. INDIVIDUALES & 4 & $26.67 \%$ & 8 & $53.33 \%$ & 3 & $20.00 \%$ & 15 \\
\hline
\end{tabular}

Fuente: Encuesta de ingresos y gastos..., Ibid. 
En Tecoluca (ver cuadro 6), en lo relativo al uso de los recursos silvestres, la situación, con algunas excepciones, es similar: los productores que presentan las peores condiciones de consumo, son precisamente los que hacen más uso de los recursos de la naturaleza; sin embargo, en términos globales, en Tecoluca los productores muestran un porcentaje en el uso de los recursos naturales, un poco menor (25\%) que el evidenciado en San Juan Opico (35\%), estos datos globales, así como los presentados en cada micro-región, no sólo deben ser vistos a la luz de la pobreza absoluta, sino también de la pobreza relativa; de este modo debe tomarse en cuenta que a pesar que observando la pobreza absoluta, el municipio que se encuentra más por encima de este parámetro es el que hace más uso de los recursos silvestres (S. J. Opico), debe, no obstante, advertirse que esa situación cambia cuando se observa la pobreza relativa; para este caso, se comprueba que el municipio que se halla más por debajo del límite de la pobreza relativa es San Juan Opico, eso debe explicar en cierta medida su mayor uso de los recursos de la naturaleza.

CUADRO 6

TECOLUCA: USO DE LOS RECURSOS NATURALES POR LOS PEQUEÑOS AGRICULTORES

\begin{tabular}{|l|r|r|r|r|r|r|r|}
\hline CATEGPROPIE. & ARREND. & DESMOVIL. & PROPIETA. & R.A. COLEC. & R. A. INDIV. & TENEDOR & TOTAL \\
\hline UTILIZA & 7 & 2 & 2 & 1 & 1 & 1 & 14 \\
\hline PORCENTAJE & $38.89 \%$ & $66.67 \%$ & $33.33 \%$ & $11.11 \%$ & $9.09 \%$ & $25.00 \%$ & $27.45 \%$ \\
\hline NO UTILIZA & 11 & 1 & 4 & 8 & 10 & 3 & 37 \\
\hline PORCENTAJE & $61.11 \%$ & $33.33 \%$ & $66.67 \%$ & $88.89 \%$ & $90.91 \%$ & $75.00 \%$ & $72.55 \%$ \\
\hline TOTAL & 18 & 3 & 6 & 9 & 11 & 4 & 51 \\
\hline PORCENTAJE & $35.29 \%$ & $5.88 \%$ & $11.76 \%$ & $17.65 \%$ & $21.57 \%$ & $7.84 \%$ & $100.00 \%$ \\
\hline
\end{tabular}

Fuente: Encuesta de ingresos y gastos..., Ibid.

En el municipio de Tecoluca la explotación de leña y la pesca representan las más importantes formas de explotación de la naturaleza; la explotación de leña representa un $81 \%$, la pesca casi un $13 \%$ y la recolección de frutas un $6 \%$; los productores que se dedican más a la explotación de la leña (un 100\% de ellos según los datos) son los desmovilizados, los propietarios, los de la Reforma Agraria colectiva y los tenedores. En este municipio, a excepción de los de la Reforma Agraria colectiva, todos participan muy poco en los programas de reforestación, incluyendo a los que hacen más usos de los recursos naturales. 


\section{CUADRO 7}

TECOLUCA: AGRICULTORES QUE REFORESTARON O NO

\begin{tabular}{|l|c|c|c|c|c|c|c|}
\hline CATEG.ACTITUD & $\begin{array}{c}\text { HA } \\
\text { SEMB }\end{array}$ & $\%$ & $\begin{array}{c}\text { NO HA } \\
\text { SEMB. }\end{array}$ & $\%$ & N.R & $\%$ & TOTAL \\
\hline ARRENDATARIOS & 1 & $5.56 \%$ & 17 & $94.44 \%$ & 0 & $0.00 \%$ & 18 \\
\hline DESMOVILIZADOS & 0 & $0.00 \%$ & 1 & $33.33 \%$ & 2 & $66.67 \%$ & 3 \\
\hline PROPIETARIOS & 1 & $16.67 \%$ & 5 & $83.33 \%$ & 0 & $0.00 \%$ & 6 \\
\hline REF. AGR. COLECTIVO & 4 & $44.44 \%$ & 4 & $44.44 \%$ & 1 & $11.11 \%$ & 9 \\
\hline REF. AGR. INDIVIDUAL & 1 & $9.09 \%$ & 10 & $90.91 \%$ & 0 & $0.00 \%$ & 11 \\
\hline TENEDOR & 1 & $25.00 \%$ & 3 & $75.00 \%$ & 0 & $0.00 \%$ & 4 \\
\hline
\end{tabular}

Fuente: Encuesta de ingresos y gastos..., Ibid.

Lo que señala el análisis de la utilización de los recursos naturales por parte de los agricultores de la encuesta, demuestra que el impacto en los ingresos reales de las políticas económicas inspiradas en el "enfoque pragmático", no están contribuyendo a generar condiciones socio-económicas que permitan que los productores hagan un uso racional de estos recursos, en el sentido de que los pequeños productores no sólo aprovechen los recursos de su medio ambiente, sino también, que lo protejan.

\section{B.2. El impacto de la política conómica en los ingresos y la economía fami- liar}

En la economía de los pequeños productores, es conocido que prácticamente toda la familia se ve envuelta en la actividad agrícola, la evidencia micro-regional es coherente con esta afirmación.

En el caso de San Juan Opico (ver cuadro 8) se comprueba que la participación femenina de la familia, en las actividades agrícolas y no agrícolas, se da en mayor proporción en los estratos en condiciones socio-económicas más difíciles, por ejemplo, para este municipio eso ocurre para el caso de los asalariados y los colonos. 


\section{CUADRO 8}

\section{S. J. OPICO: PARTICIPACION FEMENINA EN LAS ACTIVIDADES}

\begin{tabular}{|l|c|c|c|c|c|c|}
\hline ACTIV JPROPEE & ARREND. & ASALARIA. & COLONOS & PROPIETA. & R. A. INDIV & TOTA \\
\hline AGROPECUARIAS & $8.33 \%$ & $0.00 \%$ & $27.27 \%$ & $27.27 \%$ & $19.23 \%$ & $20.69 \%$ \\
\hline ASALARIADO & $8.33 \%$ & $60.00 \%$ & $27.27 \%$ & $9.09 \%$ & $3.85 \%$ & $12.64 \%$ \\
\hline COMERCIO & $8.33 \%$ & $0.00 \%$ & $0.00 \%$ & $3.03 \%$ & $3.85 \%$ & $3.45 \%$ \\
\hline PROCESAMIENTO & $0.00 \%$ & $0.00 \%$ & $0.00 \%$ & $3.03 \%$ & $0.00 \%$ & $1.15 \%$ \\
\hline SERVICIO & $8.33 \%$ & $0.00 \%$ & $0.00 \%$ & $9.09 \%$ & $0.00 \%$ & $4.60 \%$ \\
\hline ARTESANIA & $0.00 \%$ & $0.00 \%$ & $0.00 \%$ & $0.00 \%$ & $0.00 \%$ & $0.00 \%$ \\
\hline DOMESTICO & $66.67 \%$ & $40.00 \%$ & $45.45 \%$ & $48.48 \%$ & $73.08 \%$ & $57.47 \%$ \\
\hline TOTAL & $100.00 \%$ & $100.00 \%$ & $100.00 \%$ & $100.00 \%$ & $100.00 \%$ & $100.00 \%$ \\
\hline
\end{tabular}

Fuente: Encuesta de ingresos y gastos..., Ibid.

En Tecoluca, con la excepción de los de la Reforma Agraria individual, son también los productores con menores niveles de consumo, quienes presentan un mayor involucramiento de la mano de obra femenina de la familia en las labores agrícolas y no agrícolas. Cuando se comparan los datos globales de los dos municipios, se puede ver que tanto en Tecoluca como en San Juan Opico la participación femenina de la familia en la producción y generación de ingresos monetarios es importante. La mayor proporción que representa el trabajo femenino en las actividades asalariadas, en el municipio de San Juan Opico, se explica en considerable medida por la existencia de actividades industriales en el municipio y por la cercanía de San Salvador.

\section{CUADRO 9}

TECOLUCA: ACTIVIDADES EN LAS QUE PARTICIPA LA MUJER.

\begin{tabular}{|l|c|c|c|c|c|c|c|}
\hline ACTIV JPROPIE. & ARREND. & DESMOVIL & PROPIETA & R.A. COLECT & R. A. INDIV & TENEDO & PROM. TO \\
\hline AGROPECUARIAS & $27.27 \%$ & $66.67 \%$ & $12.50 \%$ & $14.29 \%$ & $58.82 \%$ & $30.77 \%$ & $31.82 \%$ \\
\hline ASALARIADO & $6.06 \%$ & $0.00 \%$ & $0.00 \%$ & $0.00 \%$ & $11.76 \%$ & $7.69 \%$ & $5.68 \%$ \\
\hline COMERCIO & $3.03 \%$ & $0.00 \%$ & $12.50 \%$ & $0.00 \%$ & $0.00 \%$ & $7.69 \%$ & $3.41 \%$ \\
\hline PROCESAMIENTO & $0.00 \%$ & $0.00 \%$ & $25.00 \%$ & $7.14 \%$ & $0.00 \%$ & $7.69 \%$ & $4.55 \%$ \\
\hline SERVICIO & $0.00 \%$ & $0.00 \%$ & $0.00 \%$ & $0.00 \%$ & $0.00 \%$ & $0.00 \%$ & $0.00 \%$ \\
\hline ARTESANIA & $0.00 \%$ & $0.00 \%$ & $0.00 \%$ & $0.00 \%$ & $0.00 \%$ & $0.00 \%$ & $0.00 \%$ \\
\hline DOMESTICO & $63.64 \%$ & $33.33 \%$ & $50.00 \%$ & $78.57 \%$ & $29.41 \%$ & $46.15 \%$ & 54.55 \\
\hline TOTAL & $\mathbf{1 0 0 . 0 0 \%}$ & $\mathbf{1 0 0 . 0 0 \%}$ & $\mathbf{1 0 0 . 0 0 \%}$ & $\mathbf{1 0 0 . 0 0 \%}$ & $\mathbf{1 0 0 . 0 0 \%}$ & $\mathbf{1 0 0 . 0 0 \%}$ & $\mathbf{1 0 0 . 0 0 \%}$ \\
\hline
\end{tabular}

Fuente: Encuesta de ingresos y gastos..., Ibid. 
Los resultados de la investigación de los dos municipios, demuestra que la población femenina dentro de los pequeños productores agropecuarios, se ve sometida a una extenuante presión y actividad laboral que abarca desde el trabajo agropecuario, asalariado, de comercio, etc. hasta el trabajo doméstico; esta última labor, como se sabe, no entra en la esfera de actividad de los hombres. Sin embargo, aun considerando que este es un problema de interacción de géneros, es de vital importancia señalar la fuerte influencia que tienen las condiciones socio-económicas que poseen los productores, las cuales a medida que son impactadas de forma más negativas por la política económica del gobierno, no sólo aumentan la miseria en general de los pequeños productores, sino que hacen todavía más duras las condiciones de vida de la mujer con respecto a la situación de los hombres.

También pudo constatarse, que en lo que respecta a la participación de los hijos varones en las actividades, la mayor parte, en los dos municipios, se ven involucrados en las actividades agrícolas y el comercio.

Los resultados de la encuesta, comprueban que las difíciles condiciones de vida de los pequeños productores agropecuarios, obliga a toda la familia a involucrarse en la actividad de generación de ingresos, lo cual hace más duras la condiciones de vida de la mujer, limita la posibilidad de estudiar de los hijos del agricultor, genera situaciones de agotamiento, debilidad y, por ende, mala salud, en todos los miembros de la familia. Es obvio que esta situación de los pequeños productores agropecuarios, tienda a complicarse con medidas de política económica que en lugar de traerles beneficio los perjudica, hasta el punto de arruinarlos y convertirlos en mano de obra asalariada.

\section{CONCLUSIONES}

- Parece ser que el modelo que predomina en la política económica del gobierno, es el que los asesores/consultores del mismo denominan "enfoque pragmático", el cual está exento de la intervención excesiva del Estado propio del "modelo intervencionista" o de la inequitativa distribución del ingreso al que conduce el "enfoque liberal". El modelo pragmático le asigna un papel normativo al Estado, en función de establecer un entorno institucional que reduzca lo que ellos llaman costos de transacción, mientras que el mercado es el que distribuye los recursos y determina los precios, la combinación de esos dos factores debe redundar en un eficiente proceso productivo y en el aumento de los ingresos de los miembros de la sociedad. Pero si todavía surgen sectores afectados por razones ajenas a las estructuras de mercado competitivas, el Estado, mientras corrige a través de políticas institucionales, debe asumir un rol de subsidiaridad para aliviar las fallas. 
- En el contexto del "enfoque pragmático" (neoliberal), los pequeños productores agropecuarios, de manera especial los de granos básicos, deben volverse eficiente o convertirse en mano de obra de las industrias, principalmente de ensamblaje, que las inversiones del capital extranjero y nacional establecerán en el país, ese es el planteamiento conceptual que se encuentra tras las decisiones de política económica del gobiemo desde 1989.

- Las medidas económicas de privatización y liberalización, hasta las estructuradas por el nuevo gobiemo de Calderón Sol, se hallan encaminadas a "reconvertir" el sector agropecuario, que para los pequeños productores no significa otra cosa que un proceso acelerado de proletarización.

- Se puede decir que la nueva administración de Calderón Sol, en lo que a la política económica se refiere, es una continuidad de las medidas económicas impulsadas por el anterior gobierno de Cristiani, con algunos cambios técnicos como el de establecer un sistema de convertibilidad con tipo de cambio fijo, que viene a sustituir al sistema de flotación "sucia" aplicado por la administración anterior.

- En lo referente a la denominada Nueva Política de Granos Básicos (NPGB), para el gobierno de Cristiani estuvo definida, en lo fundamental, a través de los mecanismos de la banda de precios, el desmantelamiento del IRA y la reserva estratégicas; el efecto que de manera explícita el gobierno pretendía alcanzar con estas medidas, no han sido conseguidos; la administración actual no hace ninguna alusión específica a la NPGB, sencillamente se ha referido a que dentro del sector agropecuario tradicional existen sólo dos alternativas: el desplazamiento o la eficiencia (la competitividad).

- A pesar de que pareciera que el gobierno de Cristiani mostró una mayor preocupación por los pequeños productores de granos básicos, bien analizadas las cosas en el marco de la política neoliberal global, se puede comprobar que también esa administración les presentó a los pequeños productores de granos las mismas dos alternativas; sólo que en la actualidad esa política pretende ser llevada hasta las últimas consecuencias.

- El impacto que las políticas neoliberales o "pragmáticas" han tenido en los ingresos reales del sub-sector de granos básicos, se han hecho sentir, tanto a nivel nacional como micro-regional, a través de los precios, la capacidad de compra, los niveles de consumo, el crédito, las condiciones técnicas de la producción y las condiciones de comercialización.

- La interacción de dos mecanismos liberalizadores, como los relativos a la desgravación del comercio exterior y a la búsqueda de la transparencia del mercado (v. gr. BOLPROES), ha incidido en el lento crecimiento de los precios nominales de los granos básicos, lo cual también se ha comprobado en lo relativo a las micro-regiones; esto se ha dado en unas condiciones en las que no 
existen políticas de ninguna clase para tratar de hacer más competitivos a estos productores, ni para transformarlos en los agentes gestores de la reconversión.

- La situación desventajosa que se da en términos de los precios nominales de los productores de granos básicos, se vuelve más seria cuando se pasa a considerar la capacidad de compra. En las micro-regiones, aunque se muestran condiciones superiores a los promedios nacionales (más alta capacidad de compra, menos porcentaje de rendimiento por manzana para adquirir insumos) al analizar la situación de forma dinámica, de igual forma que en los precios, los agricultores micro-regionales también van perdiendo su capacidad de compra como porcentaje del rendimiento.

- Es obvio que con una débil capacidad de compra, Ios agricultores debe tener un bajo estándar de consumo; en efecto, al igual que lo evidenciado en toda la nación, los productores micro-regionales también se encuentran en el umbral de la pobreza absoluta, lo que ha significado que algunos productores se encuentren ligeramente por debajo mientras que otros se encuentran ínfimamente por encima.

- Las condiciones de consumo, de los pequeños productores de granos básicos, demuestra que no se justifica en el país una política de desgravación arancelaria, pues los análisis convencionales chocan con la realidad del subdesarrollo que padece nuestro país. Si la desgravación de los granos básicos hace caer los precios de éstos, los salarios reales también caen ajustando el consumo del obrero a una canasta en donde los granos representan una considerable proporción; si los precios de los granos suben, aunque los salarios reales probablemente no suban de inmediato, deben de terminar ajustándose, de modo que en el largo plazo, en promedio, el obrero sólo gana para consumir una canasta formada aproximadamente en un $40 \%$ (en gramos) de granos básicos, en el área urbana, y en un $75 \%$ en la zona rural.

- La nueva medida de política cambiaria no deja lugar a dudas que el gobierno actual como el saliente, han sesgado esta medida a favor de los sectores transables, y en ese afán el BCR se ve obligado a incurrir en una pérdida cambiaria en la necesidad de estabilizar la circulación monetaria, al vender bonos que pagan tipos de interés más altos que los pagados por los bancos internacionales; al mismo tiempo que se incurre en esta pérdida que en realidad se transforma en subsidio para el sector de transables, al sub-sector de granos básicos se le hace cada vez más difícil tener acceso a los recurso de la banca de fomento y la banca privada. De la misma manera los ingresos tributarios, especialmente los provenientes del IVA, financian "incentivos" como el llamado "draw back" para los exportadores, mientras a los productores de granos básicos les fue eliminado todo subsidio.

- Frente a una cobertura de créditos considerablemente reducida, los producto- 
res tienen que depender de la asistencia técnica que ofrecen el gobierno y las ONG's. El servicio prestado por el Estado a nivel nacional como micro-regional es bastante bajo, sin embargo, los porcentajes de las micro-regiones analizadas se muestran más alto que el promedio nacional, aunque el promedio en las dos micro-regiones en conjunto no pasa de aproximadamente el $20 \%$, la asistencia técnica de las ONG's es pequeña en los dos municipios. Algo muy similar ocurre en cuanto al uso de equipo.

- Las condiciones de comercialización, han estado relacionadas con las acciones de "inteligencia de mercados", la capacidad de acopio que posea el productor y las medidas que el gobierno impulsa para establecer la seguridad alimentaria, esto es, las medidas vinculadas con la reserva estratégicas. Desgraciadamente, para el pequeño agricultor que carece de una infraestructura para acopio que le permita regular la oferta, tanto los mecanismos de "inteligencia de mercados (la bolsa de productos, por ejemplo), como los de la reserva estratégica, que han hecho uso excesivo de la misma en épocas de cosecha, han conducido a la depresión de los precios de los granos y a la agudización de los bajos ingresos de los pequeños productores agropecuarios.

- Es claro que ante estas condiciones tan adversas en las que se desenvuelven los pequeños productores agropecuarios, y que han sido acentuadas por las políticas económicas, la alternativa que se le va perfilando con más fuerza al pequeño productor, es la de transformarse en asalariado del capital internacional y nacional, cuyas inversiones que se esperan que ocurran, todavía no se hacen patente en nuestra economía. Con lo cual, la mencionada transformación puede que sea de productor a desempleado permanente, agudizando la ya crítica situación socio-económica del país.

- Los datos recabados a nivel de las micro-regiones en estudio, nos comprueban que los efectos que las políticas económicas generan en los ingresos, repercuten en las condiciones ambientales a través de la acción que el productor debe realizar para poder cubrir sus necesidades básicas. Cuando se analiza los niveles de consumo y se compara con los grados de explotación de los recursos naturales, se puede observar que aquellos que tienen los más bajos niveles de vida (incluso se encuentran por debajo del nivel de pobreza absoluta) son los que hacen más uso de los recursos naturales y los que menos participan en las actividades de reforestación.

- De igual forma dentro de las familias que acusan los niveles de consumo más bajos, la participación femenina es mayor. Por lo tanto, el impacto de las políticas económicas, especialmente cuando empeoran las condiciones de vida, también tiene incidencia en la economía familiar, al obligar a la mujer a tener que recargar sus labores para poder ayudar a cubrir las necesidades alimenticias de la familia. También los hijos varones en su mayoría participan en las labores agropecuarias, principalmente cuando ya han cumplido los diez años. 
1. Para una información más amplia ver: Montesino C., M. Gastos, ingresos y política ecconómica en las micro-regiones: Tecoluca y San Juan Opico. Mimeo. Proyecto Análisis de la Política Agraria, UCA/Ford; diciembre, 1995.

2. Montesino C., M. El impacto de la política económica del gobierno en el subsector de granos básicos. REALIDAD. UCA, San Salvador, septiembre-octubre, 1995.

3. Montesino, M. El impacto de la política económica del gobierno en el subsector de granos básicos de El Salvador. Mimeo. Proyecto Análisis de la Política Agropecuaria, UCA/Ford. San Salvador, agosto, 1995.

4. UAP, MAG. Política agrícola. Volumen I, agosto, 199I, p. 2.

5. UAP, MAG. Política agrícola. Op. cit.

6. OAPA, MAG. Plan económico de El Salvador 1995-1999. Análisis de sus efectos en el sector agropecuario. Política agrícola. Volumen V, No. 1. Abril, 1995. P. 5.

7. OAPA, MAG. Plan económico... Ibid. P. 6.

8. OAPA, MAG. Plan económico... Ibid. Anexos analíticos.

9. Núñez, R.; Loehr, W. El Salvador: una evaluación del efecto sobre la agricultura de Ios recientes cambios de políticas. APAP II, informe técnico, AID; diciembre, 1991. P. B-7 (anexo B).

10. “Qué es una bolsa de productos?". El Diario de Hoy. Economía y Negocios, sección Nacional, julio, 30, 1995.

11. Op. cit.

12. "El precio del maíz sigue atractivo". El Diario de Hoy. Economía y Negocios, sección Bolsa; septiembre, $1 ; 1995$

13. "Aumenta el precio del frijol de seda". El Diario de Hoy. Economía y Negocios, sección Nacional, septiembre, 4; 1995.

14. Para una mayor información consultar: Economía y Negocios. El Diario de Hoy. Julio, 30 y 31; agosto, 14;25; 29; 30; y septiembre, 1 y 4 ; de 1995.

15. OAPA, MAG. Plan económico... Ibid. P. 20.

16. Zavaleta, J. C. Investigación del sistema de producción de los granos básicos a nivel de micro-región. Mimeo. Proyecto de Análisis de la Política Agraria, UCA/Ford. Diciembre de 1994. Ver cuadros de estructura de costos de los granos básicos.

17. Los resultados sobre las condiciones de pobreza de los productores de las microregiones utilizando otros métodos son equivalentes a los que aquí presentamos. Para mayor información consultar: Montesino, M. S. Gastos, ingresos y política económica... Ibid.

18. Montesino, M. El impacto de las políticas económicas en el sub-sector de granos básicos de El Salvador. Mimeo. Proyecto Análisis de las Política Agraria. UCA/ Ford. San Salvador. Agosto, 1995.

19. Para un estudio sobre los pequeños productores a nivel nacional ver: Montesino, $M$. El impacto de las políticas económicas en el subsector de granos básicos de El Salvador. Mimeo. Proyecto de Análisis de la Política Agraria, UCA/FORD, 1995. En relación a los salarios mínimos urbanos y rurales con respecto a las canastas de consumo a nivel nacional consultar: Góchez, R.; Montesino, M. Salarios y productividad. ECA, año L, N 546, octubre, 1995.

20. "Una cuestión que se observa con bastante claridad es el hecho de que, el Estado y el gobierno como expresión del Estado, ha sido objeto de severas críticas de efectividad y eficiencia en materia económica, de ahí la justificación de constreñirle sus 
competencias productivas en el marco de los programas de ajuste estructural. No es ningún secreto... las reconocidas insuficiencias del sector público para la prestación de los servicios de su competencia. Partiendo de ese hecho, resulta contradictorio que a esas 'instituciones de lo social' se les adjudique hoy día la mayor de las tareas: la disminución de la pobreza"

“...si el Estado no fue capaz de manejar adecuadamente la gestión económica, son escasas las argumentaciones que le acrediten como el mejor para resolver los mayores males sociales de los salvadoreños. (Sánchez, Sonia I. Ayuda externa y más pobreza en El Salvador. Revista Realidad. No. 47, septiembre-octubre, 1995; pp. 763-764.

21. Laure, J. El Salvador: 1954-1991. Poder de compra de los salarios mínimos, antes y durante la guerra civil. Colección Documentos Técnicos, No. 24, INCAP; diciembre, 1993.

22. Departamento de Economía. ¿Qué modelo económico y qué modelo de sociedad queremos? Estudios Centroamericanos (ECA), año L, enero-febrero, UCA, San Salvador; 1995. Apartado relativo a la fijación del tipo de cambio. P. 40.

23. Los granos básicos se consideran convencionalmente dentro de los productos transables; aquí, en El Salvador, se podrían argüir tres razones fuertes que pondrían en tela de juicio esa concepción: una de ellas se relaciona con el hecho de que los granos básicos sólo se exportan en cantidades insignificantes, la segunda, tiene que ver con su debilidad ante la competencia de las importaciones; debido a eso el subsector ha estado protegido frente a la competencia internacional y, la tercera razón, es la relativa al hecho de que los granos básicos no logran cubrir la demanda interna. Pero se consideren como transables o no, lo cierto es que las políticas gubernamentales relativas al tipo de cambio, y en general las políticas económicas liberalizadoras del sector externo, no han favorecido al subsector de granos básicos, por lo cual debe quedar claro que cuando nos referimos al sector de transables, lo hacemos excluyendo a este subsector.

24. Departamento de Economía. ¿Qué modelo... Ibid. P. 43.

25. Tobar, J. La política de crédito... Ibid. P. 74.

26. Tobar, J. La política de crédito... Ibid. 73.

27. Departamento de Economía. ¿Qué modelo... Ibid. P. 44.

28. González C., M.; Góchez S., R. Perfil institucional del municipio de Tecoluca. Mimeo. Proyecto de Análisis de la Política Agraria. UCA/Ford. San Salvador, Agosto, 1995. P. 151-152.

29. Tobar, J. El crédito agropecuario bajo el programa de ajuste estructural. Serie de documentos de investigación. Proyecto Análisis de las Política Agropecuaria. UCA Ford. septiembre, 1995. P. 75. Ver apartado de las consideraciones finales.

30. Zavaleta, J. C. Investigación de la asistencia técnica al pequeño productor en el municipio de Tecoluca. Mimeo. Proyecto Análisis de la Política Agraria, UCA/ Ford. San Salvador, julio de 1995.

31. Norton; R.; et al. Una estrategia de desarrollo agrícola para El Salvador, 1994-2000. Documento de trabajo No. 37. FUSADES, San Salvador, septiembre, 1994. P. 73. 